Washington University School of Medicine Digital Commons@Becker

Open Access Publications

$9-2-2021$

\title{
HSP90 inhibitors reduce cholesterol storage in Niemann-Pick type C1 mutant fibroblasts
}

\author{
Nina H Pipalia \\ Weill Cornell Medical College \\ Syed Z Saad \\ Weill Cornell Medical College \\ Kanagaraj Subramanian \\ Washington University School of Medicine in St. Louis \\ Abigail Cross \\ Fordham University \\ Aisha Al-Motawa \\ Weill Cornell Medical College
}

See next page for additional authors

Follow this and additional works at: https://digitalcommons.wustl.edu/open_access_pubs

Please let us know how this document benefits you.

\section{Recommended Citation}

Pipalia, Nina H; Saad, Syed Z; Subramanian, Kanagaraj; Cross, Abigail; Al-Motawa, Aisha; Garg, Kunal; Blagg, Brian S J; Neckers, Len; Helquist, Paul; Wiest, Olaf; Ory, Daniel S; and Maxfield, Frederick R, "HSP90 inhibitors reduce cholesterol storage in Niemann-Pick type $\mathrm{C} 1$ mutant fibroblasts." Journal of lipid research. 62, 100114 (2021).

https://digitalcommons.wustl.edu/open_access_pubs/11013

This Open Access Publication is brought to you for free and open access by Digital Commons@Becker. It has been accepted for inclusion in Open Access Publications by an authorized administrator of Digital Commons@Becker. For more information, please contact vanam@wustl.edu. 


\section{Authors}

Nina H Pipalia, Syed Z Saad, Kanagaraj Subramanian, Abigail Cross, Aisha Al-Motawa, Kunal Garg, Brian S J Blagg, Len Neckers, Paul Helquist, Olaf Wiest, Daniel S Ory, and Frederick R Maxfield 


\title{
HSP90 inhibitors reduce cholesterol storage in Niemann-Pick type C1 mutant fibroblasts
}

\author{
Nina H. Pipalia ${ }^{1} \oplus$, Syed Z. Saad ${ }^{1}$, Kanagaraj Subramanian ${ }^{2}$, Abigail Cross $^{3}$, Aisha al-Motawa ${ }^{1}$, Kunal Garg $^{1}$, \\ Brian S. J. Blagg ${ }^{4}$, Len Neckers ${ }^{5}$, Paul Helquist ${ }^{4}$, Olaf Wiest ${ }^{4}$, Daniel S. Ory ${ }^{2}$, and \\ Frederick R. Maxfield ${ }^{1} *$ (C) \\ ${ }^{1}$ Department of Biochemistry, Weill Cornell Medical College, New York, NY, USA; ${ }^{2}$ Department of Internal Medicine, \\ Washington University in St. Louis, St. Louis, MO, USA; ${ }^{3}$ Natural Sciences Department, Fordham University, New York, NY, \\ USA; ${ }^{4}$ Department of Chemistry and Biochemistry, University of Notre Dame, South Bend, IN, USA; and ${ }^{5}$ Urologic \\ Oncology Branch, National Cancer Institute, Bethesda, MD, USA
}

\begin{abstract}
Niemann-Pick type C1 (NPC1) disease is a lysosomal lipid storage disorder caused by mutations of the NPC1 gene. More than 300 disease-associated mutations are reported in patients, resulting in abnormal accumulation of unesterified cholesterol, glycosphingolipids, and other lipids in late endosomes and lysosomes (LE/Ly) of many cell types. Previously, we showed that treatment of many different NPC1 mutant fibroblasts with histone deacetylase inhibitors resulted in reduction of cholesterol storage, and we found that this was associated with enhanced exit of the NPC1 protein from the endoplasmic reticulum and delivery to LE/Ly. This suggested that histone deacetylase inhibitors may work through changes in protein chaperones to enhance the folding of NPC1 mutants, allowing them to be delivered to LE/Ly. In this study, we evaluated the effect of several HSP90 inhibitors on NPC1 ${ }^{11061 T}$ skin fibroblasts. We found that HSP90 inhibition resulted in clearance of cholesterol from $\mathrm{LE} / \mathrm{Ly}$, and this was associated with enhanced delivery of the mutant NPC1 ${ }^{11061 T}$ protein to $\mathrm{LE} / \mathrm{Ly}$. We also observed that inhibition of HSP90 increased the expression of HSP70, and overexpression of HSP70 also reduced cholesterol storage in $N P C 1^{11061 T}$ fibroblasts. However, we did not see correction of cholesterol storage by arimoclomol, a drug that is reported to increase HSP70 expression, at doses up to $0.5 \mathrm{mM}$. Fir The increase in other chaperones as a consequence of HSP90 improves folding of NPC1 protein and relieves cholesterol accumulation in NPC1 mutant fibroblasts.
\end{abstract}

Supplementary key words cholesterol • drug therapy • fluorescence microscopy - endocytosis - Niemann-Pick disease • lysosomal storage $\cdot \mathrm{HSP} 90 \cdot \mathrm{HSP} 70 \cdot$ chaperone $\bullet$ arimoclomol

Niemann-Pick type Cl (NPCl) disease is a neurovisceral lysosomal storage disease caused by mutations in both alleles of the NPC1 gene. The incidence of

*For correspondence: Frederick R. Maxfield, frmaxfie@med. cornell.edu. occurrence in juveniles is estimated to be about one in 92,000 , but with the inclusion of mutations associated with late-onset disease, the frequency increases to one in 20,000-36,000 (1). Over 300 disease-associated mutations are reported (1-6), and biallelic mutations lead to abnormal accumulation of unesterified cholesterol, glycosphingolipids, and other lipids in late endosomes and lysosomes (LE/Ly) of many cell types. The most common mutation, I1061T, is present in at least one allele of about $20 \%$ of patients (7). The clinical spectrum of NPCl disease is very broad, ranging from a rapidly progressing fatal neonatal disorder to adult-onset neurodegeneration (8-10). NPC1 is a lysosomal glycoprotein with 13-transmembrane domains that is synthesized and folded with the aid of chaperones in the endoplasmic reticulum (ER) (11-14), where it acquires $14 \mathrm{~N}$-linked glycans $(15,16)$. After exit from the ER, the NPCl protein is exported to the Golgi and subsequently targeted to LE/Ly compartments (17). Many mutations in NPC1 result in protein misfolding and impaired trafficking of the protein out of ER, followed by protein degradation (ER-associated protein degradation) $(11,18)$. This results in significant reduction of NPC1 protein levels compared with WT cells $(11,18)$. Lack of sufficient NPC1 protein in the LE/Ly leads to impaired cholesterol exit from these organelles.

There is no Food and Drug Administration-approved therapy to treat NPCl disease. Intrathecal delivery of 2-hydroxypropyl beta-cyclodextrin (HPCD) was shown to slow disease progression in a phase 1/2a trial $(19,20)$, prompting a phase $2 \mathrm{~b} / 3$ trial. A limitation of HPCD is that it does not cross the blood-brain barrier, requiring direct injection into the CNS. In a search for an orally available treatment, we showed that histone deacetylase inhibitor (HDACi) treatment of skin fibroblasts results in increased expression of NPC1 protein in mutant cells because of enhanced folding and exit from the ER (21). Using an engineered human cell line, we also observed that broad-spectrum HDACis can correct the NPC1 
cholesterol storage defect in 60 of the 81 NPC1 mutants tested (18). These studies indicated that many of the mutant proteins could function adequately if they were delivered to LE/Ly. However, a study in a mouse model of $N P C 1^{I 1061 T}$ (22) indicated that an HDACi (Vorinostat) provided no benefit in a whole animal model (23).

Nevertheless, the correction in cell culture indicated that the HDACis were assisting in correction of the disease phenotype for many NPC1 mutations. In order to understand the molecular mechanism of HDACi on NPCl, we considered potential cellular effects of HDACi treatment. It has been shown that the $\mathrm{NPC1}^{\text {I1061T }}$ mutant protein undergoes ER-associated protein degradation, presumably associated with the inability to fold efficiently in the ER (11). Boosting chaperone activity has been proposed as a method to correct the defect in NPCl mutant cells (12, 24-26). Changes in molecular chaperone activity are one of the many consequences of HDACi treatment (14, 27, 28). A quantitative proteomic analysis of the response to HDACi in NPCl human fibroblasts revealed that the expression of proteins associated with protein folding was modulated (29). A detailed study of the response of many NPC1 mutations to allosteric modulators showed that many of the mutations were rescued to some degree by these modulators, which alter the interactions of HSP70 with cochaperones (14). It has been shown that HSP90 as well as HSP70 can play a role in stabilization and correct folding of NPC1 (12).

Several HSP90 inhibitors have gone through extensive clinical testing as potential cancer therapeutics (30). We tested the effect of HSP90 inhibitors on the expression, folding, and activity of NPC1 in human fibroblasts that were homozygous for the $N P C 1^{11061 T}$ allele, expecting that this would exacerbate the phenotype. Surprisingly, we found that HSP90 inhibition aided in transporting mutant NPC1 protein from the ER to LE/Ly, which led to increased clearance of cholesterol from LE/Ly. Molecular chaperones form a complex network to assist in protein folding in cells (31). HSP70 family members are key members of the chaperone family, and we confirmed that HSP90 inhibition led to an increase in HSP70 expression as reported previously $(32,33)$. In addition, transfection of cells with HSP701A (HSPA1A) led to a reduction in cholesterol storage in NPC1 $1^{I 061 T}$ cells. We tested arimoclomol, which is reported to increase expression of HSP70 and other chaperones (34), but we did not see an increase in HSP70 expression or a reduction in cholesterol storage in $N P C 1^{I 1061 T}$ cells.

\section{MATERIALS AND METHODS}

\section{Reagents}

Gibco ${ }^{\circledR}$ McCoy's 5A medium, MEM, FBS, HBSS, penicillin/ streptomycin, Geneticin (G418), AlexaFluor-546 N-hydroxy succinimidyl ester, and AlexaFluor 546 goat anti-rabbit and
AlexaFluor 488 goat anti-rat antibody were purchased from Invitrogen Life Technologies Corporation (Carlsbad, CA). HSP90 inhibitors were from various suppliers: 17-AAG (Geldanamycin) from Reagent Direct (Encinitas, CA), AUY922 (luminespib), ganetespib, and AT13387 (onalespib) from Selleckchem (Houston, TX) or from the Blagg laboratory at Notre Dame (35), SNX2112 from Esanex (Indianapolis, IN), TAS-116 from Taiho Pharmaceuticals (Tokyo, Japan), and arimoclomol maleate (arimoclomol) from MedKoo Biosciences. Glucose-regulated protein 94 (GRP94) inhibitors were obtained from the Blagg laboratory and prepared as described in references in Table 1 . All compounds were dissolved at 10 or $1 \mathrm{mM}$ in dimethyl sulfoxide (DMSO) and stored at $-20^{\circ} \mathrm{C}$. Acetylated LDL was prepared by acetylation of LDL with acetic anhydride (40). AlexaFluor-546 labeled human LDL (LDLA546) was prepared as described (41, 42). Rabbit polyclonal antihuman NPCl (p-Rab anti-hNPCl) antibody was purchased from Abcam (Cambridge, MA), rabbit polyclonal anti-HSP40 (p-Rab anti-HSP40), anti-HSP70 (p-Rab anti-HSP70), and antiHSP90 (p-Rab anti-HSP90) were purchased from Cell Signaling (Danvers, MA). A p-Rab anti-hNPCl antibody was used for EndoH Western blotting assay. All other chemicals, including (DMSO, 99\% fatty-acid free bovine serum albumin, filipin, paraformaldehyde (PFA), and Hepes were purchased from Sigma Chemical (St. Louis, MO). Draq5 was from Biostatus (Leicestershire, UK), and Metamorph image-analysis software was from Molecular Devices (Downington, PA).

\section{Cell culture}

Human fibroblast cells. Human NPC1 fibroblasts GM18453 (homozygous NPC1 mutant I1061T) were from Coriell Institute (Camden, NJ). All human skin fibroblasts were maintained in MEM supplemented with 10\% FBS. For the inhibitor treatments, cells were maintained in MEM supplemented with $5.5 \% \mathrm{FBS}$ and $20 \mathrm{mM}$ Hepes.

NPC1 null cells (U2OS-SRA ${ }^{\text {shNPC1 }}$ ). Stable U2OS-SRA-shNPC1 cells (18) were cultured in McCoy's 5A medium supplemented with $10 \%$ FBS, 50 -units $/ \mathrm{ml}$ penicillin, $50 \mu \mathrm{g} / \mathrm{ml}$ streptomycin, $5 \mu \mathrm{g} / \mathrm{ml}$ puromycin, and $1 \mathrm{mg} / \mathrm{ml} \mathrm{G} 418$.

\section{Effect of HSP90 and GRP94 inhibitor treatment on human fibroblasts}

The dose dependence of six HSP90 inhibitors (17-AAG, AUY922, ganetespib, AT13387, SNX2112, and TAS-116) and Grp94 inhibitors (BB1-5) was determined after 72-h treatment of NPC1 fibroblasts. Human $N P C 1^{11061 T}$ fibroblasts were seeded in 384-well plates at 450 cells/well in growth medium on day 1. After overnight incubation, compounds were added at six different doses diluted in growth medium supplemented with $20 \mathrm{mM}$ Hepes buffer and 5.5\% FBS. DMSO was used as a

TABLE 1. GRP94 inhibitors

\begin{tabular}{|c|c|c|c|c|c|}
\hline \multirow{3}{*}{$\begin{array}{l}\text { Compound no. } \\
\text { BB-1 }\end{array}$} & \multicolumn{3}{|c|}{ Affinities-apparent $K_{d(\mu \mathrm{M})}$} & \multirow{2}{*}{\multicolumn{2}{|c|}{$\begin{array}{l}\text { Fold selectivity } \\
\text { for GRP94 }\end{array}$}} \\
\hline & \multirow{2}{*}{$\frac{\text { GRP94 }}{0.44}$} & \multirow{2}{*}{$\begin{array}{r}\mathrm{HSP} 90 \alpha \\
8.3\end{array}$} & \multirow{2}{*}{$\frac{\mathrm{HSP} 90 \beta}{\mathrm{ND}}$} & & \\
\hline & & & & 19 & (36) \\
\hline BB-2 & 0.2 & 8.1 & ND & 41 & (36) \\
\hline BB-3 & 0.54 & 39.2 & ND & 73 & (37) \\
\hline BB-4 & 8.5 & 18.2 & 0.44 & 42 & (38) \\
\hline BB-5 & 0.44 & $>100$ & ND & $>200$ & (39) \\
\hline
\end{tabular}

ND, not determined. 
control in each plate for each concentration. After $72 \mathrm{~h}$, the plate was washed with PBS three times, fixed with $1.5 \%$ PFA, and stained with $50 \mu \mathrm{g} / \mathrm{ml}$ filipin and nuclear stain Draq5. Measurements were made from four wells for each condition in each experiment, and the experiment was repeated three times. Images were acquired on an ImageXpress ${ }^{\text {Micro }}$ automatic fluorescence microscope, at four sites per well and analyzed to obtain the lysosome-like storage organelles (LSOs) compartment ratio, which is a measure of filipin labeling of stored cholesterol per cell (43). In other words, the LSO ratio is the perinuclear filipin intensity (PFI) per cell. A high PFI per cell is associated with high levels of cholesterol in LE/Ly. Removal of this cholesterol leads to reduction in the PFI per cell. The PFI per cell for each concentration was normalized to the corresponding DMSO-treated control.

Time and dose-dependence assay. The dose dependence of two HSP90 inhibitors, 17-AAG and AUY922, was determined as a function of time after 24,48 , and $72 \mathrm{~h}$ treatment of $N P C 1^{I 1061 T}$ fibroblasts (GM18453). To maintain the same density of cells at the final time point, compounds were added chronologically. After overnight incubation, compounds were diluted in growth medium supplemented with $20 \mathrm{mM}$ Hepes buffer and $1 \% \mathrm{FBS}$ and added in the first plate (for 72-h time point). In the second plate, compounds were added $48 \mathrm{~h}$ after seeding the cells and allowed to incubate for $48 \mathrm{~h}$. In the third plate, compounds were added $72 \mathrm{~h}$ after seeding the cells and allowed to incubate for $24 \mathrm{~h}$. DMSO was used as a control in each plate for each concentration. All three plates were rinsed, fixed, stained, and analyzed as described previously.

\section{Fluorescence microscopy}

An automated ImageXpress ${ }^{\text {Micro }}$ imaging system from Molecular Devices equipped with a 300W Xenon-arc lamp from PerkinElmer, 10X Plan Fluor 0.3 numerical aperture objective from Nikon, and a Photometrics CoolSnapHQ camera (1,392 × 1,040 pixels) from Roper Scientific was used to acquire images. Filipin images were acquired using $377 / 50 \mathrm{~nm}$ excitation and $447 / 60 \mathrm{~nm}$ emission filters with a 415 dichroic long-pass filter. GFP images were acquired using $472 / 30 \mathrm{~nm}$ excitation and 520/35 nm emission filters with a 669 dichroic long-pass filter. Filter sets assembled in Nikon filter cubes were obtained from Semrock (Rochester, NY).

Images were also acquired using a Leica DMIRB microscope (Leica Mikroscopie und Systeme GmbH, Germany) equipped with a Princeton Instruments (Princeton, NJ) cooled charge-coupled device camera driven by Image 1/MetaMorph Imaging System software (Universal Imaging Corporation, PA). Images were acquired using a high-magnification oil immersion objective $(63 \times, 1.4$ numerical aperture objective). Filipin images were acquired using an A4 filter cube obtained from Chroma Technology Corp (Brattleboro, VT) with 360$\mathrm{nm}$ (20-nm bandpass) excitation filter and 465-nm (40-nm bandpass) emission filter.

\section{Imaging and analysis}

A method described previously was used to quantify the cholesterol accumulation in LSOs. NPC1 mutant cells show a bright region of filipin labeling near the cell center, corresponding to the sterol-loaded LSOs. The 384-well plates containing cells were imaged for filipin using a $10 \times 0.3$ numerical aperture objective dry objective on an ImageXpress $^{\text {Micro }}$ automatic fluorescence microscope. Four images were acquired from each well. Images were analyzed using
MetaXpress image-analysis software. First, all images were corrected for slightly inhomogeneous illumination as described previously (43). A background intensity value was set as the fifth percentile intensity of each image, which corresponds to intensity outside the cells, and this intensity value was subtracted from each pixel in the image. At the plating density used in this study, all fields maintain at least $5 \%$ of the imaged area cell free. We calculated the LSO ratio, which is the ratio of filipin fluorescence intensity in the brightly labeled centers of the cells in the field divided by the total area of the cells. The LSO ratio is determined using two thresholds that are applied to the filipin images. A low threshold is set to include all areas occupied by cells. The outlines of cells using the low threshold are similar to the cell outlines in transmitted light images. A higher threshold is then set to identify regions brightly stained with filipin in cells. The thresholds were chosen for each experiment.

$$
\begin{aligned}
\text { LSO ratio }(\mathrm{PFI})= & \text { total intensity above high } \\
- & \text { thresholded filipin intensity/ } \\
& \text { number of pixels above low } \\
- & \text { thresholded filipin intensity. }
\end{aligned}
$$

\section{Amplex Red assay for cholesterol}

GM18453 cells were plated in 96-well plates and treated with DMSO or AUY922 at different concentrations for $72 \mathrm{~h}$. For free cholesterol quantification, an Amplex Red assay kit (Abcam; catalog no. ab65359) was used following the manufacturer's protocol for lipid extraction and fluorometric measurement.

\section{NPC1 immunolocalization in NPC1 ${ }^{\mathrm{I1016T}}$ human fibroblasts}

GM18453 cells were treated with 100 nM AUY922 or DMSO solvent control for $72 \mathrm{~h}$. Cells were then incubated with $50 \mu \mathrm{g} /$ ml Alexa546-LDL in MEM growth medium supplemented with $5.5 \%$ FBS and $100 \mathrm{nM}$ AUY922 or DMSO solvent control for $4 \mathrm{~h}$, rinsed with growth medium, and chased in MEM growth medium supplemented with 5.5\% FBS for $30 \mathrm{~min}$. Cells were washed three times with PBS and then fixed with $1.5 \%$ PFA in PBS. For immunostaining, cells were permeabilized with $0.5 \%$ saponin and $10 \%$ goat serum in PBS for $30 \mathrm{~min}$. Cells were incubated with $0.8 \mu \mathrm{g} / \mathrm{ml}$ p-Rab anti-hNPCl primary antibody for $2 \mathrm{~h}$ in the presence of $0.05 \%$ saponin and $0.5 \%$ goat serum at room temperature, followed by Alexa488-labeled goat antirabbit secondary antibody (1:1,000; Life Technologies, Grand Island, NY) for $45 \mathrm{~min}$ at room temperature. Finally, cells were washed three times with PBS, and images were acquired using a Zeiss LSM 880, Airyscan confocal microscope equipped with a Plan-Apochromat $63 \times$ oil DIC M27 objective and 488 and 561 lasers. Z-stacks were acquired using a step size equivalent to one airy unit.

\section{Image analysis for measuring colocalization}

To measure colocalization, a previously described method was used $(44,45)$. The images were first corrected for the background intensity. Next, a threshold was applied to the Alexa488 images representing NPCl protein. A mask was generated and transferred to the Alexa546 image representing LE/Ly compartments containing LDL. The intensity in the region under the mask was recorded representing the 
colocalized region. The ratio of intensity in the Alexa546positive region and total threshold region (Alexa488 + Alexa546) gives percent colocalization.

\section{Endoglycosidase $\mathrm{H}$ assay}

Vehicle control or HSP90 inhibitor-treated $N P C 1^{I 1061 T}$ mutant fibroblasts were lysed with RIPA lysis buffer and endoglycosidase $\mathrm{H}$ (EndoH) assay was performed as described previously (46). For EndoH analysis of NPC1 protein, $20 \mu \mathrm{g}$ of cell lysates were incubated in $4 \times$ SDS sample buffer in the presence or the absence of EndoH overnight at $37^{\circ} \mathrm{C}$. The lysates were resolved on SDS-PAGE followed by immunoblotting with p-Rab anti-hNPC1, p-Rab anti-HSP90, and p-Rab anti-GAPDPH antibodies. The fraction of the intensities of EndoH-sensitive $\left(\right.$ EndoH $\left.^{\mathrm{S}}\right)$ and EndoH-resistant $\left(\right.$ EndoH $\left.^{\mathrm{R}}\right)$ bands for each condition were quantified and plotted.

\section{Western blotting}

Western blot analysis was performed on HSP90 inhibitortreated human NPC1 mutant fibroblasts to measure the expression of NPC1, HSP40, HSP70, and HSP90 using rabbit polyclonal antibodies to NPC1, HSP40, HSP70, and HSP90. Anti- $\alpha$ tubulin was used as a loading control. Secondary antibodies were from Pierce for ECL or from Molecular Devices for Eu label.

\section{Overexpression of HSP40 and HSP70}

For HSP40, NPC1 human fibroblasts were transfected with either eGFP-vector (pCMV6-AC-GFP tagged cloning vector; catalog no. PS100010; Origene Technologies) or eGFP-HSP40 (DNAJB11 [NM_016306] Human Tagged ORF Clone; catalog no. RG200216; Origene Technologies) plasmid using an Amaxa human dermal fibroblast kit and T20 protocol. For HSP70, NPG1 human fibroblasts were transfected with either eGFP-vector or eGFP-HSP70 (Addgene; catalog no. 15215) plasmid using an Amaxa human dermal fibroblast kit and manufacturer-recommended U2OS protocol. After nucleofection, cells were plated in 2-cm poly D-lysine coated coverslip dishes. Cells were incubated for $72 \mathrm{~h}$, washed with PBS, fixed with $1.5 \%$ PFA, and stained with $50 \mu \mathrm{g} / \mathrm{ml}$ filipin. Widefield fluorescence microscope images were acquired using FITC and UV filters and a $10 \times$ objective. Images were analyzed to determine LSO (PFI per cell) ratio values in GFPlabeled cells as described previously.

\section{RESULTS}

\section{Activity of HSP90 inhibitors in lowering lysosomal cholesterol storage in NPC1 mutant cells}

We tested the effects of six HSP90 inhibitors on lysosomal cholesterol accumulation in $N P C 1^{11061 T}$ mutant human fibroblasts. Cells plated in 384-well plates were treated with 17-AAG (47), AUY922 (47), ganetespib (48), AT13387 (49-51), SNX2112 (52), or TAS116 (53) at concentrations ranging from $0.5 \mathrm{nM}$ to $10 \mu \mathrm{M}$ depending on the reported potency of the compounds. The fibroblasts were treated with inhibitors for $72 \mathrm{~h}$ followed by fixation, staining with filipin and Draq5, and fluorescence microscopy analysis. Free (i.e., unesterified) cholesterol levels in perinuclear compartments brightly labeled by filipin in LSOs/PFIs were measured as described previously $(21,43)$. All data were normalized to matched DMSO controls; so a value of one indicates no correction, and values below one indicate reduction of stored free cholesterol. Figure $1 \mathrm{~A}$ shows the effects of six HSP90 inhibitors. All the inhibitors tested showed dose-dependent effects after a 72-h treatment. AUY922 was the most potent compound, and it partially corrects the NPCl phenotype below 0.5 $\mathrm{nM}$. The dotted line on the plot indicates DMSO control, and the value of one means no correction. The black trace in the plot shows the PFI in DMSO-treated WT GM5659 fibroblasts. The effectiveness of some of the HSP90 inhibitors was reduced at higher concentrations, and we saw a similar reversal with high concentrations of HDACi (21). This may be due to the pleiotropic effects of HSP90 inhibition. The effective concentrations of the HSP90 inhibitors in this assay were generally comparable to values for blocking the growth of cancer cells in culture (49, 50, 52-54), although there was variability of the potency of the compounds in blocking different tumor cells. Detailed statistical analysis was performed using GraphPad Prism software, and the $P$ values calculated using the ANOVA Kruskal-Wallis multiple comparison test are shown in supplemental Fig. S1A-F. There is a large variation in the published $\mathrm{IC}_{50}$ values for HSP90 inhibitors. Even with cell-free assays, the reported values for some inhibitors vary widely (55-59). Nevertheless, there was fair correlation between the biochemical $\mathrm{IC}_{50}$ and the midpoint of LSO/PFI curves. For instance, the reported $\mathrm{IC}_{50}$ for ganetespib is $5 \mathrm{nM}(59)$, and we see the half maximal effect at $5 \mathrm{nM}$. For TAS-116, the reported

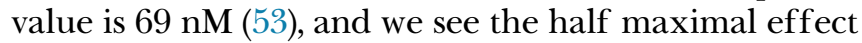
near that dose.

Representative low-magnification images of GM18453 cells treated with DMSO or optimal concentrations of all HSP90 inhibitors are shown in Fig. 1B. Images shown were acquired at $10 \times$ magnification on automated high-throughput microscope ImageXpress $^{\text {Micro. }}$. Representative high-magnification images acquired using a $63 \times$ objective are also shown in Fig. 1C. The images in the figure are of NPCl skin fibroblasts GM18453 treated with DMSO and HSP90 inhibitors at optimal concentrations labeled with filipin. All HSP90 inhibitors tested show substantial reduction in free cholesterol in PFI compared with DMSO-treated cells. The reduction in free cholesterol in HSP90 inhibitortreated cells was similar to the reduction we reported previously for cells treated with $10 \mu \mathrm{M}$ vorinostat (21).

We compared changes in free cholesterol in GM18453 cells using filipin and an Amplex Red assay of cholesterol. Since the Amplex Red assay measures total free cholesterol, we compared this with the total filipin fluorescence per cell. As shown in Fig. 2A, there is only a slight drop in total cholesterol as the LSOs are cleared off cholesterol, and the filipin and Amplex Red values show very similar effects. The small effect on total cholesterol is in agreement with earlier studies 
A

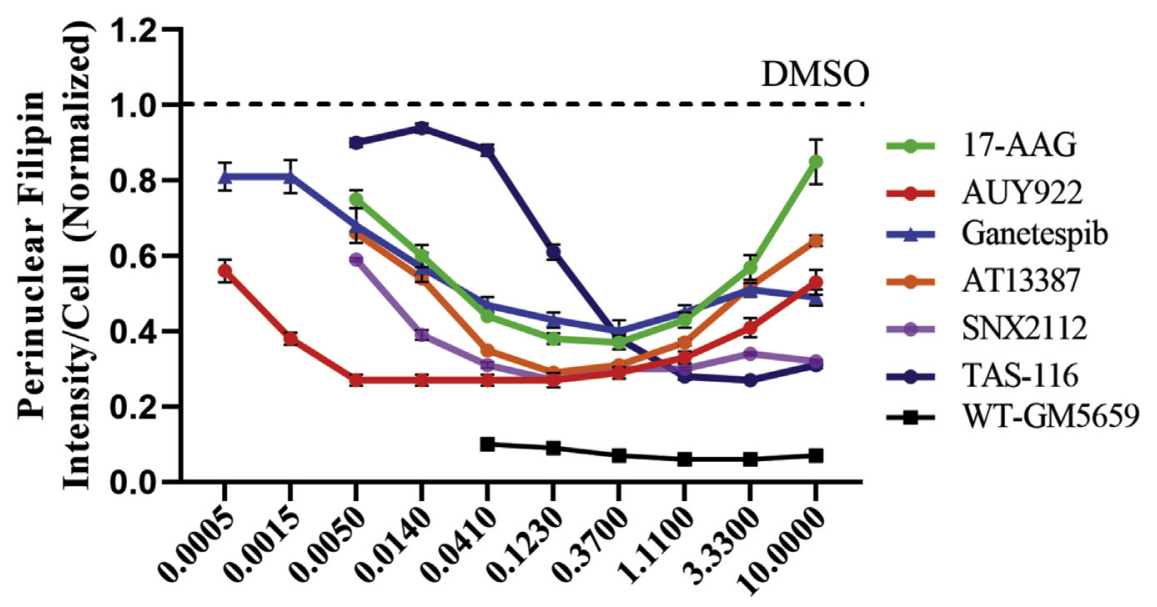

B

\section{[Concentration] $\mu \mathrm{M}$}
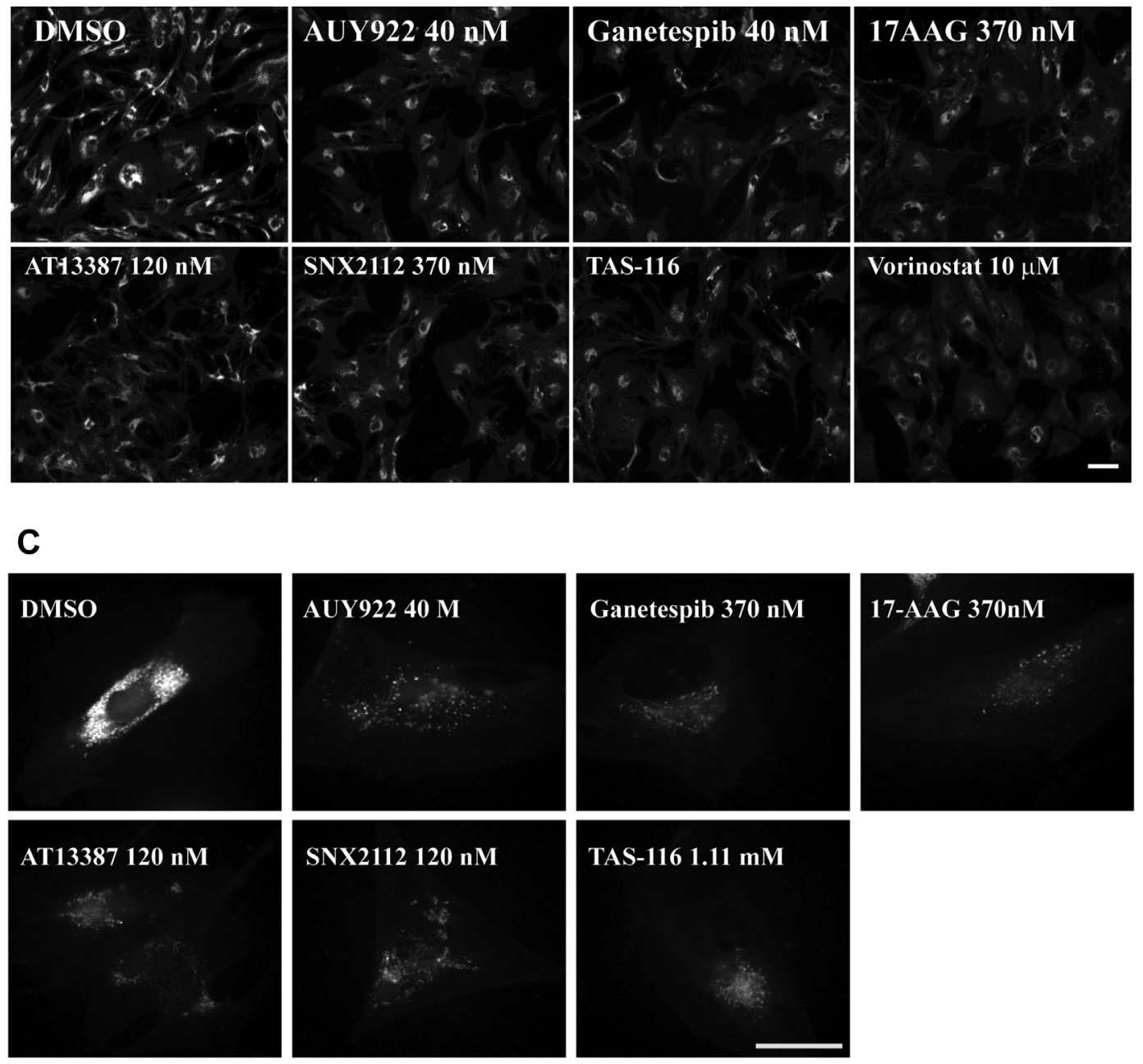

Fig. 1. Effect of HSP90 inhibitors on GM18453 NPC1 human fibroblasts: A: GM18453 fibroblast (homozygous I1061T) cells were treated with HSP90 inhibitors 17-AAG, AUY922, ganetespib, AT13387, SNX2112, TAS-116, and DMSO-treated WT-GM5659 at various doses for $72 \mathrm{~h}$, fixed, and stained with filipin and Draq5. Images were acquired on an ImageXpress ${ }^{\text {Micro }}$ using $10 \times$ magnification. Each data point is an average of the PFI per cell values from 48 images. Each image contains about 500-700 cells. Each data point in the plot is from three independent experiments \pm SE. LSO values in DMSO-treated cells were measured in each experiment for normalization and shown as a dotted line. The value of one indicates no correction. B: Representative low-magnification highthroughput filipin images of GM18453 cells treated with DMSO or optimal concentrations of HSP90 inhibitors acquired using 10x objective are shown. Vorinostat treatment was used as a positive control. The filipin intensity in perinuclear organelles of cells 


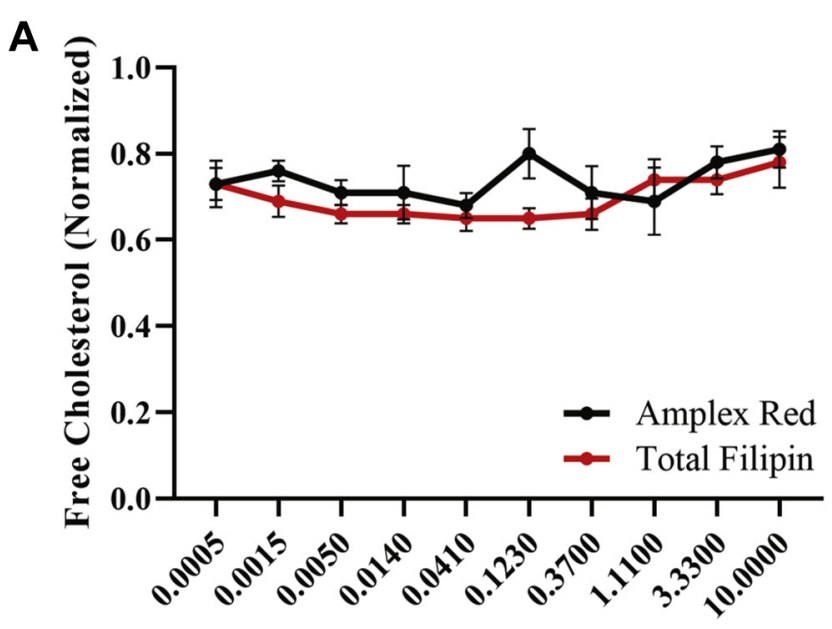

[AUY922] $\mu \mathrm{M}$

B

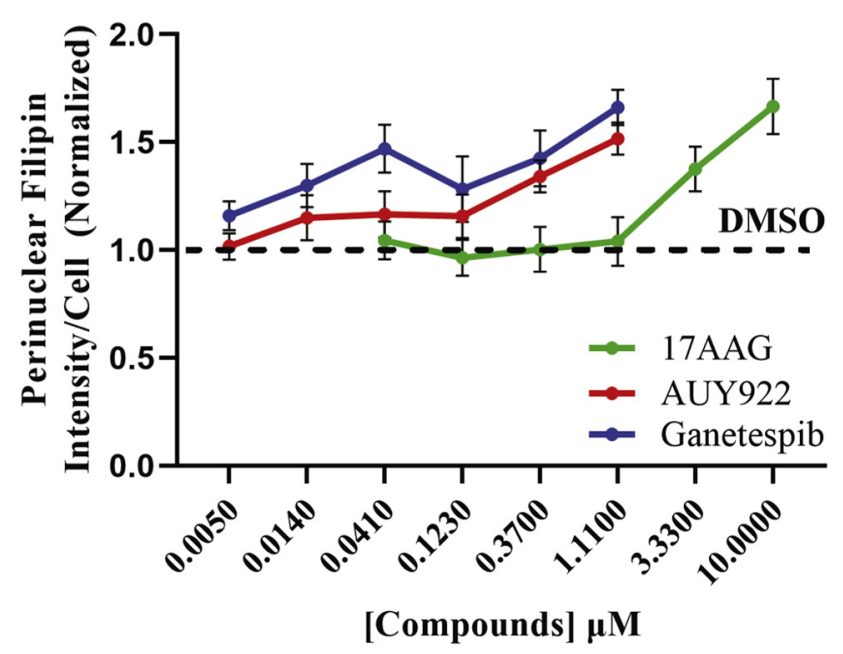

Fig. 2. A: Total cholesterol estimation. A plot showing total cholesterol concentration in AUY922-treated GM18453 cells as measured by Amplex Red biochemical method (black) and average filipin per cell (red). Error bar represents SE. B: Treatment of HSP90 inhibitors on $U 2 O S^{\text {shNPC1 }}$ cells. U2OS-SRAshNPC1 cells were treated with HSP90 inhibitors at varying doses ranging from $5 \mathrm{nM}$ to $10 \mathrm{mM}$ for $72 \mathrm{~h}$, fixed, and stained with filipin and Draq5. Images were acquired on an ImageXpress $^{\text {Micro }}$ using a $10 \times$ objective. Each data point is an average of 48 images. Each image contain $~ 500-700$ cells. Each data point in the plot is from three independent experiments. Error bar represents $\pm \mathrm{SE}$.

that showed that NPC mutant cells have elevated cholesterol in the LSOs, but elsewhere, the cholesterol content is reduced (60). To test whether the observed effect depended on the expression of the mutant NPC1 protein, we treated U2OS-SRA ${ }^{\text {shNPCl }}\left(\mathrm{NPC1}^{-/-}\right)$cells with three HSP90 inhibitors at varying concentrations for $72 \mathrm{~h}$. The PFIs per cell were measured by filipin labeling as described previously. Figure 2B shows that there was no correction of the NPCl phenotype in these cells, demonstrating that the effect observed is specific for cells carrying a mutant NPC1 protein and not an NPC1-independent effect similar to HPCD treatment (61).

\section{Time course of HSP90 inhibitors on NPC1 ${ }^{11061 T}$ fibroblasts}

We measured the time course for effects of HSP90 inhibitors on $N P C 1^{I 1061 T}$ mutant human fibroblasts. Figure 3 shows the effect of 17-AAG and AUY922 at various doses after 1,2 , or 3 days. Neither of the inhibitors tested had a large effect at $24 \mathrm{~h}$, but both showed dose-dependent effects at $48 \mathrm{~h}$ and similar or somewhat greater effects after 72-h treatment. This time course is consistent with the need to synthesize and transport new NPC1 proteins to LE/Ly in response to the drug treatment as has been proposed for HDACi treatment $(11,18,21)$. The $\mathrm{t}_{1 / 2}$ of WT NPC1 protein that has passed beyond the ER is 1-2 days (11), and a similar lifetime was observed for NPCI ${ }^{\mathrm{In} 061 \mathrm{~T}}$ in human fibroblasts treated with vorinostat (18).

\section{AUY922 treatment rescues the trafficking of mutant NPC1 protein in NPC1 ${ }^{11061 T}$ fibroblasts}

In cultured fibroblasts, approximately half of the WT NPC1 protein is degraded rapidly, and for many mutants, most of the synthesized protein is degraded with very little reaching the $\mathrm{LE} / \mathrm{Ly}(11,18)$. To measure export of $\mathrm{NPCl}^{\mathrm{I1061T}}$ out of the ER, we measured acquisition of resistance to EndoH, which occurs after proteins are exported from the ER. We measured the effect of AUY922 on acquisition of EndoH $^{\mathrm{R}}$ using a method described by Balch et al. (29, 62-64). The cell lysates from DMSO and AUY922-treated $N P C 1^{I 1061 T}$ fibroblasts were incubated with EndoH to cleave immature high-mannose $N$-linked glycans found in the $\mathrm{ER}$, resulting in an increase in migration using SDSPAGE $\left(\right.$ EndoH $\left.^{\mathrm{S}}\right)$. In immunoblots, the band intensities for $\mathrm{EndoH}^{\mathrm{R}}$ and $\mathrm{EndoH}^{\mathrm{S}}$ bands were measured (Fig. 4A, B). Treatment of NPC1I ${ }^{1061 T}$ fibroblasts with AUY922 substantially increases exit from the ER as shown by the decrease in $\mathrm{EndoH}^{\mathrm{S}}$ fraction (clear bars) after AUY922 treatment in a dose-dependent manner. The data from two separate experiments are shown in Fig. S2.

treated with HSP90 inhibitors is reduced, demonstrating the clearance of cholesterol. DMSO, AUY922 (40 nM), ganetespib (40 nM), 17-AAG (370 nM), AT13387 (120 nM), SNX2112 (370 nM), TAS-116 (3.33 $\mu$ M), 17-AAG (370 nM), and vorinostat (10 $\mu$ M), Size bar represents $100 \mu \mathrm{m}$. C: Representative high-magnification filipin images of NPC1 GM18453 fibroblast treated with HSP90 inhibitors at optimal concentrations acquired using 63× objective are shown. DMSO, AUY922 (40 nM), ganetespib (370 nM), 17-AAG (0.37 $\mu$ M), AT13387 (120 nM), SNX2112 (120 nM), and TAS-116 (1.11 $\mu \mathrm{M})$. Size bar represents $50 \mu \mathrm{M}$. 
A

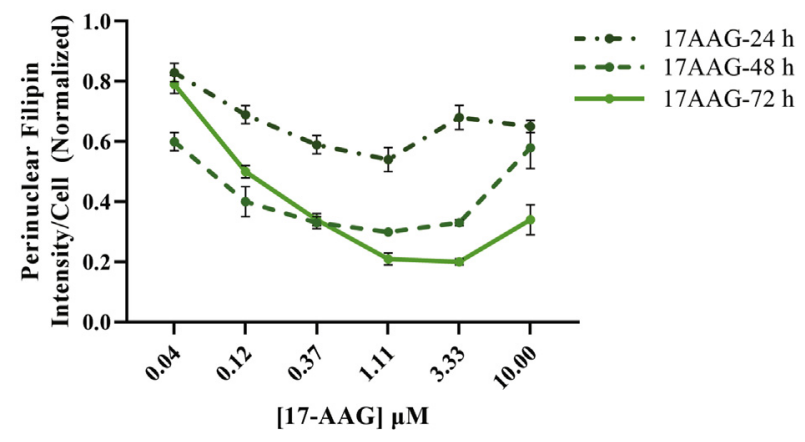

B

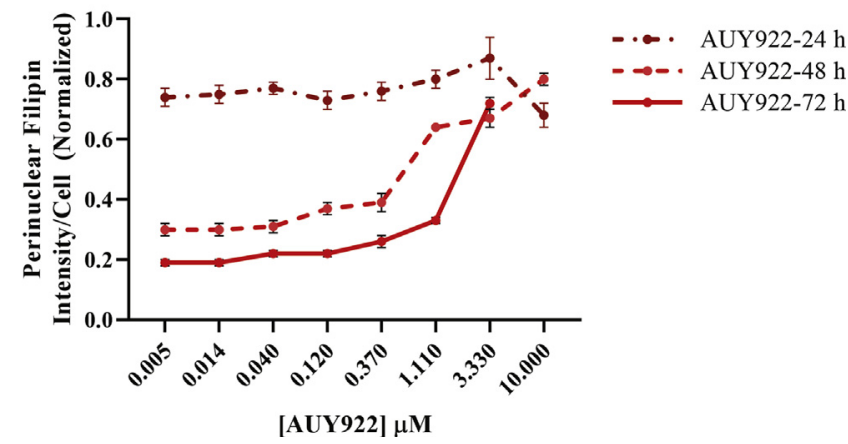

Fig. 3. Time course of treatment with HSP90 inhibitors: GM18453 fibroblasts were treated with A. 17-AAG or B. AUY922 at varying doses for 24,48 , and $72 \mathrm{~h}$, fixed, and stained with filipin and Draq5. Images were acquired on an ImageXpress $^{\text {Micro }}$ using a $10 \times$ objective. Each data point is an average of 500-700 cells per image and 48 images. Each data point in the plot is from three independent experiments. Error bar represents \pm SE.

\section{Colocalization of NPC1 and LDL}

To determine whether treatment with an HSP90 inhibitor improved trafficking of $\mathrm{NPCl}^{\mathrm{I1061T}}$ protein to LE/Ly, we treated GM18453 NPC1 $1^{I 1061 T}$ cells with 100 nM AUY922 or solvent control DMSO for $72 \mathrm{~h}$. The cells were then incubated with Alexa546 LDL for $3.5 \mathrm{~h}$ followed by a $0.5 \mathrm{~h}$ chase to deliver labeled LDL to LE/ Ly $(45,65,66)$. The fibroblasts were fixed, and NPC1 protein was detected by immunofluorescence (Fig. 4C). Representative sum projected images are shown. Additional representative images are also shown in Fig. S3. The mutant NPCl protein does not colocalize with Alexa546 LDL in LE/Ly in the DMSO-treated cells (i.e., red and green puncta are not colocalized). After $72 \mathrm{~h}$ of treatment with $100 \mathrm{nM}$ AUY922, a large fraction of the mutant NPC1 protein localizes in yellow puncta in the overlay, showing that NPCl and LDL are in the same organelles. The quantification of the Alexa488 (NPC1) signal colocalizing with Alexa546 LDL after either DMSO or AUY922 (100 nM) treatment was carried out as described in the Materials and methods section (44, 45). Shown in Fig. $4 \mathrm{D}$ are the data from two independent experiments, and each dot represents a single image. The data show that AUY922 treatment results in a significant increase in colocalization of NPCl with endocytosed LDL. This indicates that treatment with AUY922 leads to delivery of the mutant NPC1 to the organelles in which LDL is releasing cholesterol, and this NPCl ${ }^{\mathrm{I} 1061 \mathrm{~T}}$ effectively aids in transporting cholesterol out of these organelles.

\section{Effect of HSP90 inhibitor treatment on expression of other proteins}

Chaperone-mediated protein folding involves synchronized interplay of multiple chaperones and cochaperones, so inhibiting one protein results in perturbation/modulation of other chaperones and cochaperones in the pathway. It has been reported that inhibiting HSP90 results in upregulation of HSP70 in cells $(67,68)$. HSP90 inhibitors do not generally change the expression of the HSP90 protein, but they inhibit its activity by binding at the $\mathrm{N}$-terminal catalytic ATPbinding site $(36,37,54,69)$. To further understand the mechanism by which HSP90 inhibitors reverse the NPC1 mutant phenotype, we measured the expression of HSP90, HSP70, and HSP40 as well as the NPC1 protein.

NPCI ${ }^{11061 T}$ human fibroblasts were treated with either 17-AAG $(1 \mu \mathrm{M})$, AUY922 (40 nM), ganetespib (100 $\mathrm{nM}$ ), or DMSO (vehicle control). After $72 \mathrm{~h}$ of treatment with compounds or solvent control, cells were lysed, followed by immunoblot analysis. Figure 5A shows representative bands from one experiment. Average band intensities for three independent experiments were quantified and normalized to loading control (tubulin) and compared with the parallel DMSO-treated band (Fig. 5B). The dots shown on each bar represents values from independent experiments, and the data plotted are \pm SE. The results indicate that HSP90 inhibitor treatment results in significant increases in expression of NPC1, HSP70, and HSP40, but there is no significant change in HSP90 expression. The increase in HSP70 and HSP40 expression after HSP90 inhibitor treatment is in agreement with previously published reports $(12,38,39,67,68)$.

\section{HSP70 (HSPA1A) overexpression}

In order, to determine whether increased HSP70 expression plays a role in correction of the NPCI ${ }^{\mathrm{II061T}}$ mutant phenotype, we overexpressed HSP70 in NPC1 ${ }^{I 1061 T}$ human fibroblasts. We transiently transfected eGFP-HSP70 in GM18453 cells. Representative images for eGFP-Vector transfected and eGFP-HSP70 transfected cell are shown in Fig. 5C. Figure 5D shows the plot of PFI in GFP-positive cells that overexpressed either Vector (control) or HSP70. The data plotted are from three independent experiments (35, 40-44) images, and each dot represents a single cell. We tried to determine if the level of HSP70 expression is correlated with the decrease in cholesterol accumulation (Fig. S4A, B). Even a small amount of HSP70 overexpression 
A

\begin{tabular}{llllll}
\hline DMSO & \multicolumn{4}{c}{ I1061T } \\
\cline { 2 - 6 } & 0.1 & 0.5 & 1.0 & 5.0 & 10
\end{tabular}

EndoH - + - + + - + - + +

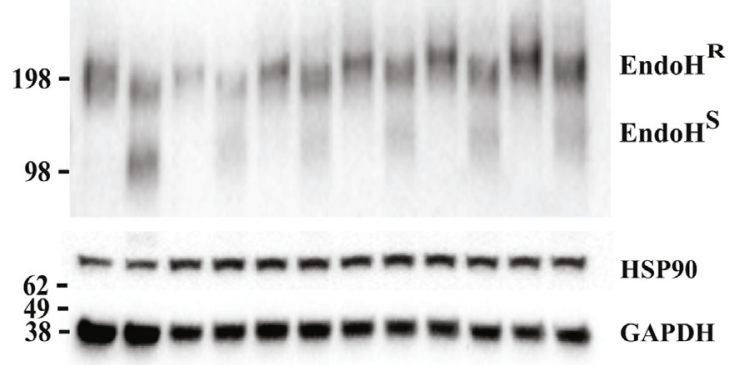

$72 \mathrm{~h}$ Drug treatment
B

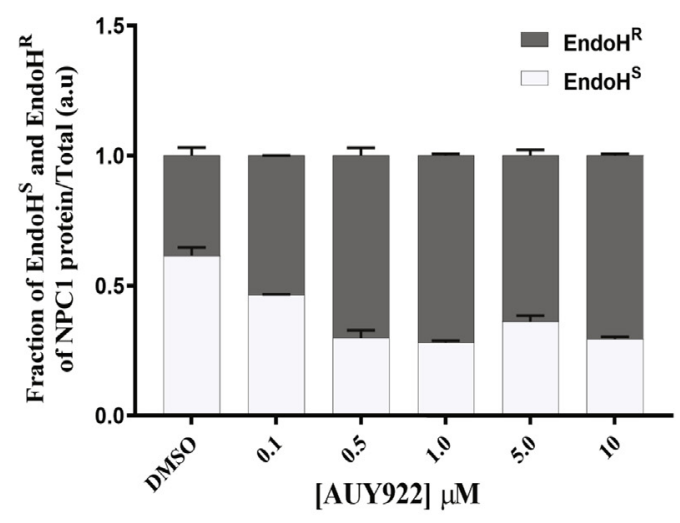

C

Transmitted

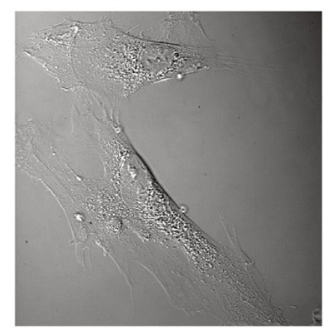

DMSO

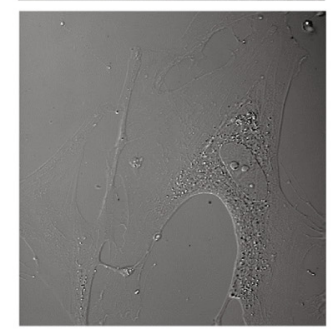

NPC1
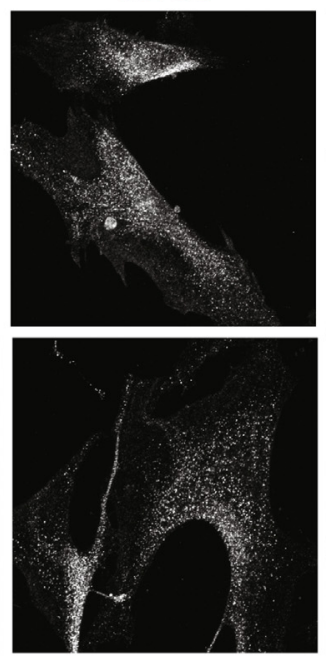

LDL
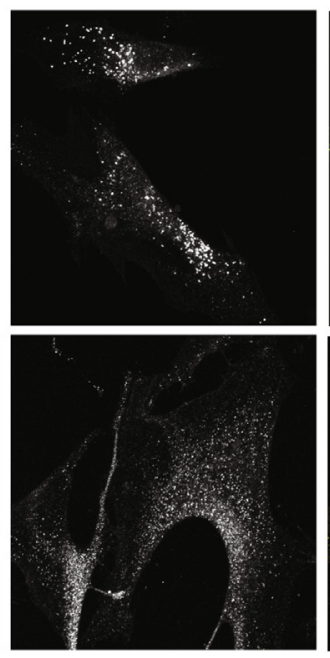
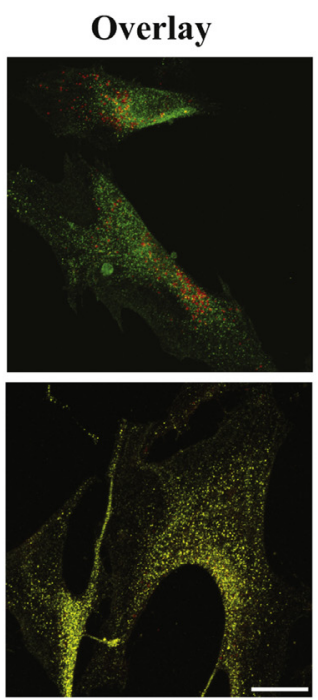

D

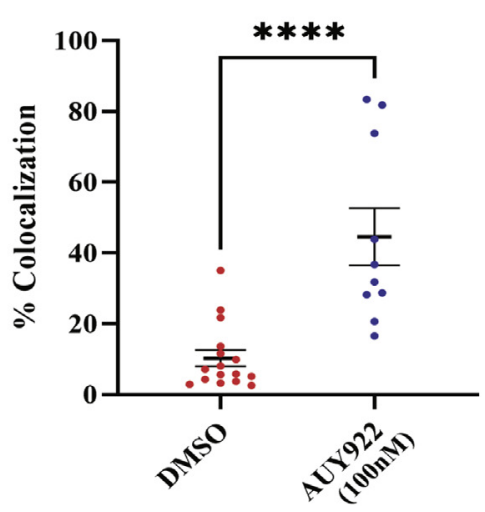

Fig. 4. Localization and stability of NPC1 protein after HSP90 inhibitor treatment. A: GM18453 cells were treated with AUY922 at varying doses for $72 \mathrm{~h}$, after which cells were lysed with RIPA lysis buffer. For EndoH analysis of NPC1 protein, $20 \mu \mathrm{g}$ of cell lysates were treated in the presence or the absence of EndoH overnight at $37^{\circ} \mathrm{C}$. The lysates were resolved on SDS-PAGE followed by immunoblotting with p-Rab anti-hNPC1, p-Rab anti-HSP90, and p-Rab anti-GAPDH antibodies. B: The fraction of the intensities of EndoH $^{\mathrm{S}}$ and $\mathrm{EndoH}^{\mathrm{R}}$ bands for each condition. C: GM18453 fibroblasts were treated with $100 \mathrm{nM}$ AUY922 or solvent control DMSO for $72 \mathrm{~h}$. The cells were incubated with Alexa-546 LDL for $3.5 \mathrm{~h}$ followed by a $0.5 \mathrm{~h}$ chase to deliver labeled LDL to LE/Ly. The fibroblasts were fixed and immunostained with primary p-Rab-anti hNPCl antibody followed by goat-anti-Rab-A488 labeled secondary antibody and detected by immunofluorescence. Images were acquired by confocal microscopy. Representative transmitted 
resulted in a reduction in PFI when compared with control Vector. These results indicate that the increased expression of HSP70 aids in rescuing the NPC1 $1^{11061 T}$ mutant phenotype.

\section{HSP40 (DNAJB11) Overexpression}

HSP40 is a co-chaperone of HSP70, so we tested the role of HSP40 expression in the correction of NPC1 $1^{I 061 T}$ mutant phenotype. We overexpressed HSP40 in NPC1 ${ }^{I 1061 T}$ human fibroblasts by transiently transfecting eGFP-HSP40 in GM18453 cells. Representative images for eGFP-vector transfected and eGFPHSP40 transfected cells are shown in Fig. 5E. Figure $5 \mathrm{~F}$ shows a plot of the LSO ratio in GFP-positive cells that did or did not overexpress HSP40. The data are from three independent experiment (24-30) images, and each dot represents a single cell. As with HSP70 overexpression, even a small level of HSP40 expression reduced the PFI (Fig. S4C, D), and there was only a small benefit at most from higher levels of HSP40. These results indicate that the increased expression of HSP40 also results in rescuing the $N P C 1^{I 1061 T}$ mutant phenotype.

\section{GRP94 inhibitors}

The HSP90 family of genes includes HSP90A (cytosolic), $H S P 90 B$ (ER), and tumor necrosis factor receptorassociated protein (mitochondrial) proteins. The inhibitors that we described so far are pan inhibitors or just inhibit HSP90A (TAS-116) (70). The TAS-116 results indicated that inhibition of the cytosolic form of HSP90 alone was effective. In order to examine another HSP90 isoform, we tested inhibitors selective for the ER-resident HSP90B1 class of chaperones, GRP94 (71-76). GM18453 fibroblasts were treated with five different GRP94 inhibitors (Table 1) for $72 \mathrm{~h}$, and the PFI per cell was measured (Fig. 6). The GRP94-selective compounds did not rescue the NPC1 ${ }^{11061 T}$ phenotype. These data indicate specificity for cytosolic HSP90A inhibition in rescuing NPCl phenotype.

\section{HSP70 activators}

It has been reported that arimoclomol reduces the size of lysosomes in $\mathrm{NPC1}^{-/-}$fibroblasts, and it reduced the ataxia and improved behavioral symptoms in an $\mathrm{Npcl}^{-/-}$mouse model (34). The compound arimoclomol has been described as an HSP70 coinducer, but we could find no peer-reviewed publications supporting this. The efficacy and safety of arimoclomol is being tested on NPC1 patients in a clinical trial (77). We tested arimoclomol on GM18453 human NPCl fibroblasts at concentrations ranging from 1.6 to $500 \mu \mathrm{M}$ for 3 or 5 days (Fig. 7A). We did not observe correction of the cholesterol storage in NPC1 $1^{I 1061 T}$ human fibroblasts. At higher concentrations and longer exposure, the phenotype worsened as shown by increases in the PFI per cell. In order to determine whether arimoclomol upregulates HSP70 protein expression in our cell culture model, we performed Western blot analysis on GM18453 cells treated with arimoclomol (50 and 400 $\mu \mathrm{M}$ ) for 3 and 5 days (Fig. $7 \mathrm{~B}$ ) and plotted the results from three independent experiments (Fig. 7C). The results indicate that arimoclomol treatment by itself does not upregulate HSP70 expression in GM18453 fibroblasts.

\section{Cotreatment of arimoclomol with AT13387 and heat shock transcription factor la}

Since treatment with HSP90 inhibitors increased HSP70 expression, we tested whether arimoclomol in combination with one of the HSP90 inhibitors would show synergistic effects. NPCl human fibroblasts GM18453 were treated with compounds one day after plating. Cells were treated with arimoclomol at $0,0.5,1$, $2,10,40$, and $100 \mu \mathrm{M}$ in combination with AT13387 (onalespib) at $0,0.04,0.12,0.37,1.11,3.33$, and $10 \mu \mathrm{M}$ and compared against DMSO-treated controls. The range of drug dosages was made to contain a large gradient of concentrations in screening media as described previously (43). Figure 7D shows the heat map of the combination treatments. The treatment with AT13387 did show correction of NPCl phenotype as expected, but there was no statistically significant synergistic effect from including arimoclomol.

Heat shock transcription factor 1 (HSF1) is the master regulator of HSP gene transcription (78). Arimoclomol is described as a coactivator that prolongs the binding of activated HSF1 to heat shock elements in the promoter regions of inducible HSP genes (79). A study of beneficiary effects of arimoclomol in NPCl disease reported that NPC1 fibroblasts subjected to heat shock exhibited activation of HSF1 (34). Hence, we tested the effect of arimoclomol in combination with HSF1activating compound HSFla $(80,81)$ and measured the cholesterol level using the LSO filipin assay. As shown in Fig. S5, we did not see a beneficial effect of HSFla with or without arimoclomol.

\section{DISCUSSION}

We report here that treatment of NPCl mutant human fibroblasts with several HSP90 inhibitors at nanomolar concentrations leads to clearance of the accumulated cholesterol in the LE/Ly of human homozygous NPC1 ${ }^{11061 T}$ fibroblasts in a dose-dependent manner. Based on the ineffectiveness of these inhibitors on

light and sum projected images of fluorescently labeled NPC1 and LDL are shown. Size bar represents $25 \mu \mathrm{m}$. D: Quantification of the colocalization of Alexa488 (NPC1) and Alexa546 (LDL) signals after either DMSO or AUY922 (100 nM) treatment. The data are from two independent experiments, and each dot represents single image. Mann-Whitney statistical analysis (GraphPad Prism) was used. $P<0.0001$. 
A

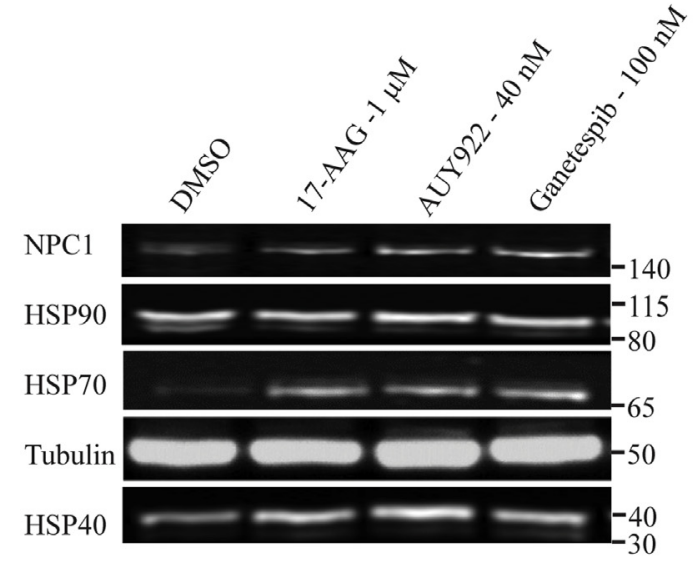

B

C

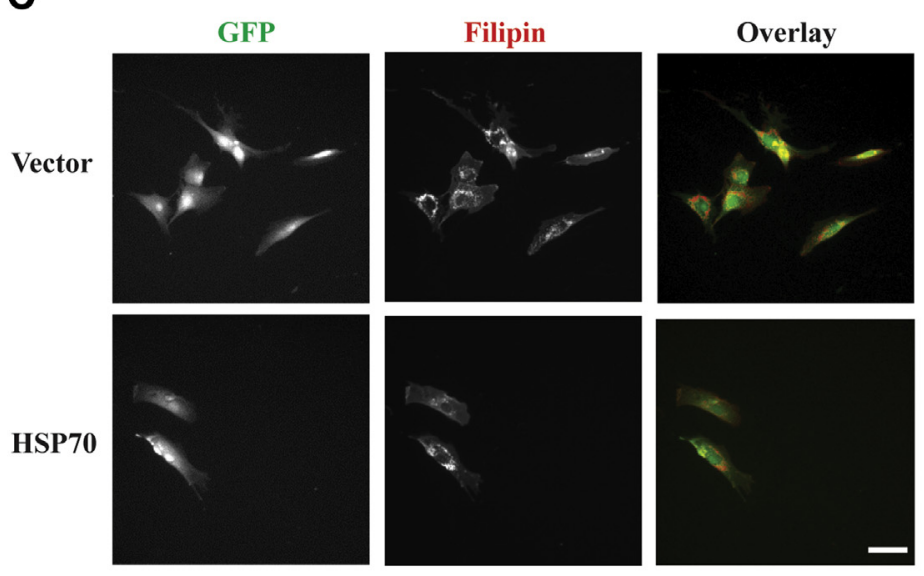

E
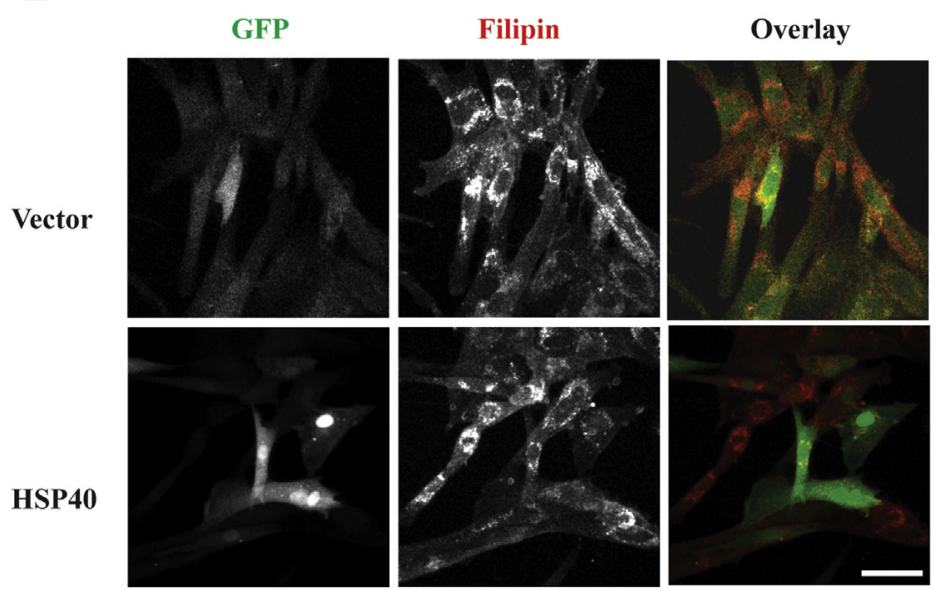

D

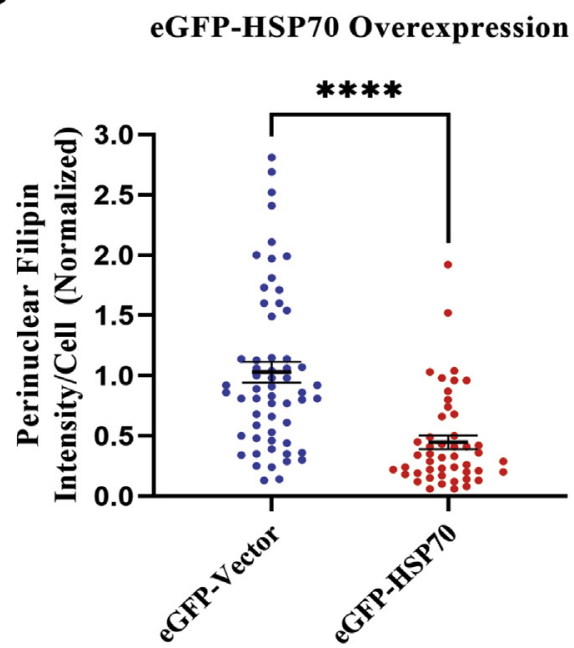

$\mathbf{F}$
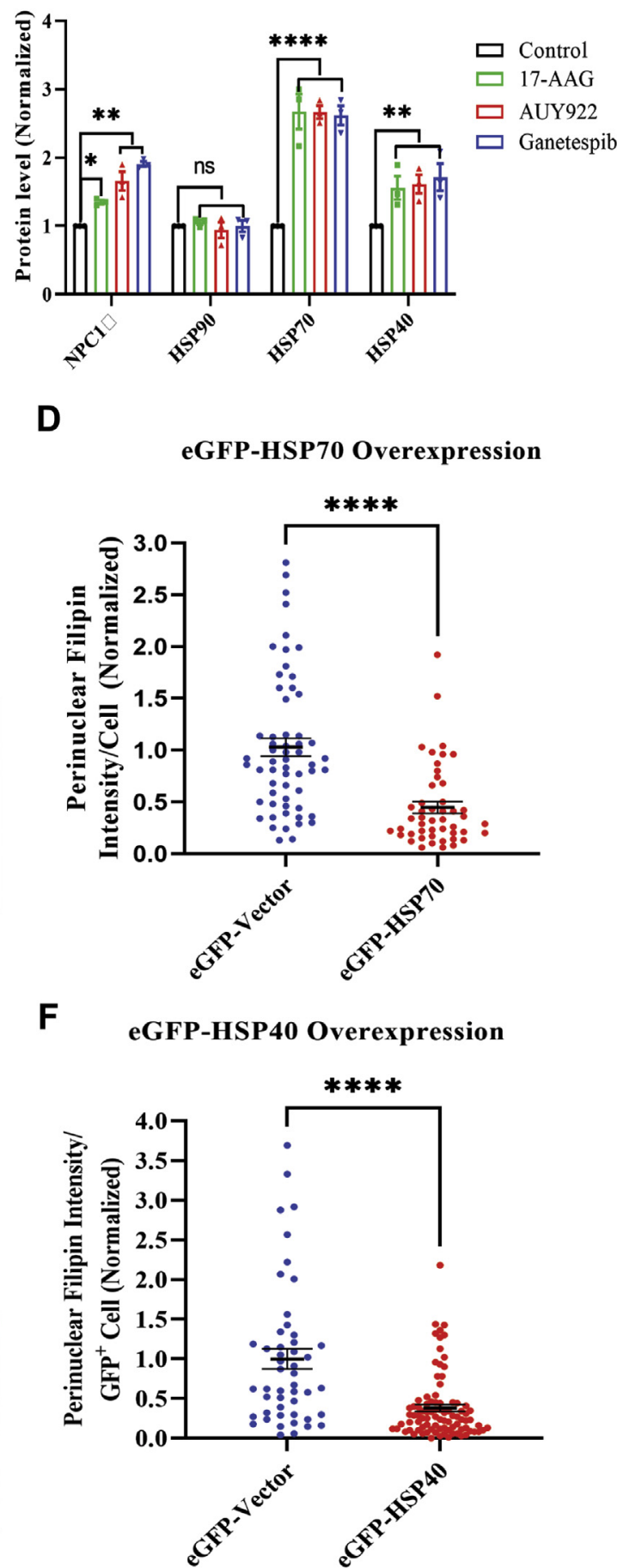

Fig. 5. Effect of HSP90 inhibitors on expression of other chaperones: GM18453 fibroblasts were treated with $17-\mathrm{AAG}(1 \mu \mathrm{M})$, AUY922 (40 nM), or ganetespib $(100 \mathrm{nM})$. As a control, cells were treated with DMSO. After $72 \mathrm{~h}$ of treatment with compounds or solvent control, cells were lysed and immunoblotted for various proteins. After resolving bands on 4-12\% Bis-Tris gel, proteins were transferred to a PVDF membrane and probed with p-Rab anti-hNPC1 antibody, p-Rab anti HSP70, p-Rab anti HSP40, and p-Rab anti HSP90. Tubulin (mouse monoclonal) was used as a loading control. A: Lane 1: DMSO; lane 2: $1 \mu$ M 17-AAG; lane 3: 40 nM AUY922; and lane 4: $100 \mathrm{nM}$ ganetespib. B: Plot showing quantification of immunoblot bands normalized to tubulin and DMSO-treated fibroblasts. Dotted indicates DMSO control. $P$ values for NPC1, HSP90, HSP70, and HSP40 were 17-AAG (green): 0.001, not significant (ns), 0.008, 0.05; AUY922 (red): 0.03, ns, 0.0002, 0.03 and ganetespib (blue): 0.0001, ns, 0.0009, 0.05, respectively. C: GM18453 cells were transiently transfected with eGFP-vector or eGFP-HSP70 and incubated for $72 \mathrm{~h}$. Cells were washed with PBS, fixed with $1.5 \%$ PFA, 


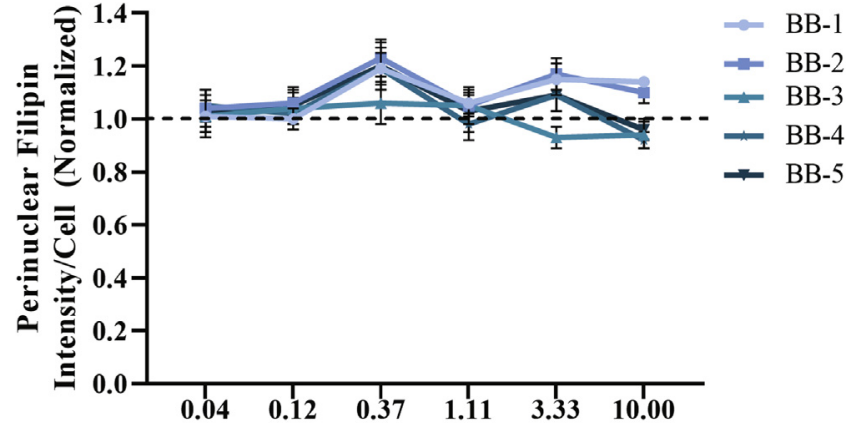

[Grp94 Inhibitors] $\mu \mathrm{M}$

Fig. 6. Effect of GRP94 Inhibitors on NPC1 cells: GM18453 fibroblasts were treated with GRP94 inhibitors BB1, BB2, BB3, $\mathrm{BB} 4$, and BB5 at varying doses for $72 \mathrm{~h}$, fixed, and stained with filipin and Draq5. Images were acquired on ImageXpress ${ }^{\text {Micro }}$ using a $10 \times$ objective. Each data point is an average from three experiments and 72 images total, each image contained $\sim 300-500$ cells. Error bar represent \pm SE.

$\mathrm{NPCl}^{-/-}$cells, we infer that the clearance is due to a direct impact on the NPC1 protein and not a general bypass of the NPC1-dependent pathways as is seen in cells treated with cholesterol-chelating cyclodextrins (61).

The beneficial effect of HSP90 inhibitors is associated with improved trafficking of the NPCl protein out of the ER and delivery to LE/Ly. In untreated cells, the majority of $\mathrm{NPCI}^{\mathrm{Il} 061 \mathrm{~T}}$ protein is EndoH sensitive, indicating failure to exit the ER (29). After the treatment with AUY922 for 3 days, the majority of the $\mathrm{NPCI}^{\mathrm{I1}}{ }^{261 \mathrm{~T}}$ has exited the ER and shows good colocalization with internalized LDL in LE/Ly. In order to start understanding how inhibition of HSP90 might improve folding of $\mathrm{NPCl}^{\mathrm{I1061T}}$ and its exit from the ER, we examined he effects of HSP90 inhibitors on expression of other chaperone proteins. As reported previously, HSP70 and HSP40 levels were increased when HSP90 was inhibited (32, 33), and this was accompanied by an increase in NPCl protein in the cells. Transient overexpression of HSP70 or HSP40 also reduced the cholesterol storage significantly. Although proper folding of proteins is facilitated in the ER by various molecular chaperones, RNA-Seq data in cells treated with AUY922 or onalespib did not show an increase in binding protein, calnexin, or calreticulin (data not shown). It is unclear how even slightest increase of cytosolic chaperones such as HSP40 and HSP70 (Figs. 5C-F and S4A-D) affect the folding of NPCl, which has relatively small cytoplasmic sequences. Various mechanisms have been proposed for the rescue of NPC1 mutant cells by increasing HSP70. One study claims that increasing HSP70 can rescue $\mathrm{NPCl}^{-/-}$cells, which suggests that there are other unknown mechanisms for rescue of cholesterol storage (82). Another article suggests that HSP70 can affect the proteostasis of mutant NPCl-allowing more of the mutant NPC1 to exit the ER as a properly folded protein (14). A third article proposes that HSP70 can extend the lifetime of NPCl by blocking ubiquitination and proteasomemediated degradation (12). Thus, further in-depth studies will be required to understand the detailed mechanism by which cytosolic HSP90/HSP70/HSP40 chaperone machinery is involved in folding of large transmembrane-spanning protein like NPCl.

A recent study examined the effects of modulating the HSP70 chaperone/cochaperone complex on a large number of NPC1 variants (14). That study focused on the effects of an allosteric inhibitor, JG98, which alters the interactions of HSP70 with cochaperones, especially the Bcl-2-associated athanogene family of cochaperones $(83,84)$. As with the study of HDACis (18), it was found that JG98 corrected the ER retention and degradation of many NPC1 variants (14). This study examined SREBP2 activity, which is affected by the release of cholesterol from LSOs, and the results indicate that JG98 was facilitating release of cholesterol from LSOs in NPC1 $1^{I 1061 T}$ cells. Overall, our results corroborate these findings on the importance of HSP70 and other chaperones and extend them by directly

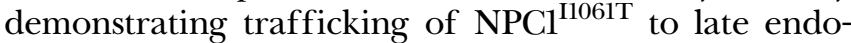
somes and lysosomes containing LDL and showing reduction of filipin-labeled cholesterol in these organelles. Much additional work will be required to develop optimal strategies to target these chaperone networks to treat NPC1 patients.

Since NPCl protein is folded initially in the ER, we tested inhibitors of the ER-specific member of the HSP90 family, GRP94 (72-74, 76). The GRP94-selective inhibitors were not effective in rescuing the cholesterol storage defect in $N P C 1^{11061 T}$ cells. This is consistent with a downstream effect of HSP90 inhibitors, such as increasing cytosolic HSP70 expression, rather than a direct effect of an HSP90 protein on the NPC1 protein in the ER. Our data showing rescue of NPCl phenotype with HSP40 overexpression are in agreement with published reports. It has been shown that treatment of HEK293 cells with 17-AAG increases the expression of HSP70 mRNA, and the effect is enhanced by a mild

and stained with $50 \mu \mathrm{g} / \mathrm{ml}$ filipin. Images were acquired using GFP and A4 filters using a 20× dry objective. Size bar represents $25 \mu \mathrm{m}$. D: PFI was measured in GFP-positive cells and plotted. Dot plots showing data from three independent experiments \pm SE. Each dot represents an individual cell. Mann-Whitney statistical test was performed, $P<0.0001$. E: GM18453 cells were transiently transfected with eGFP-vector or eGFP-HSP40 and incubated for $72 \mathrm{~h}$. Cells were washed with PBS, fixed with $1.5 \%$ PFA, and stained with $50 \mu \mathrm{g} / \mathrm{ml}$ filipin. Images were acquired using GFP and A4 filters using a 20× dry objective. Size bar represent $10 \mu \mathrm{m}$. F: PFI was measured in GFP-positive cells and plotted. Dot plots showing data from three independent experiments \pm SE. Each dot represents an individual cell. Mann-Whitney statistical test was performed, $P<0.0001$. 


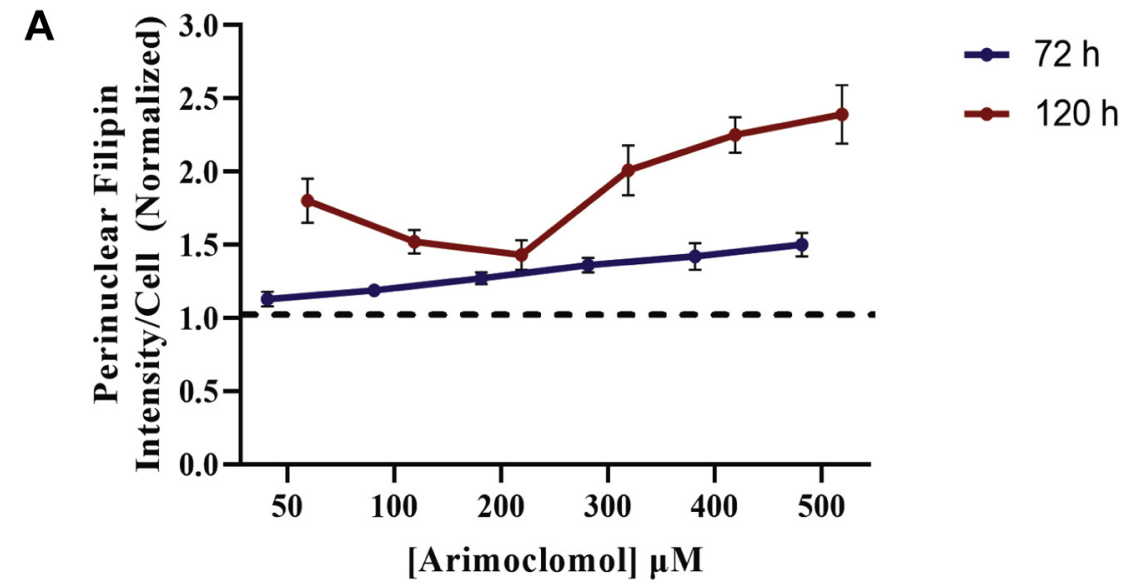

B

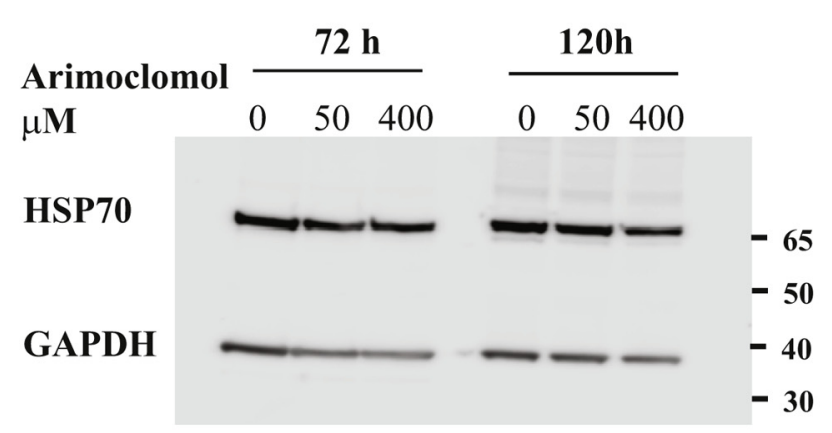

C

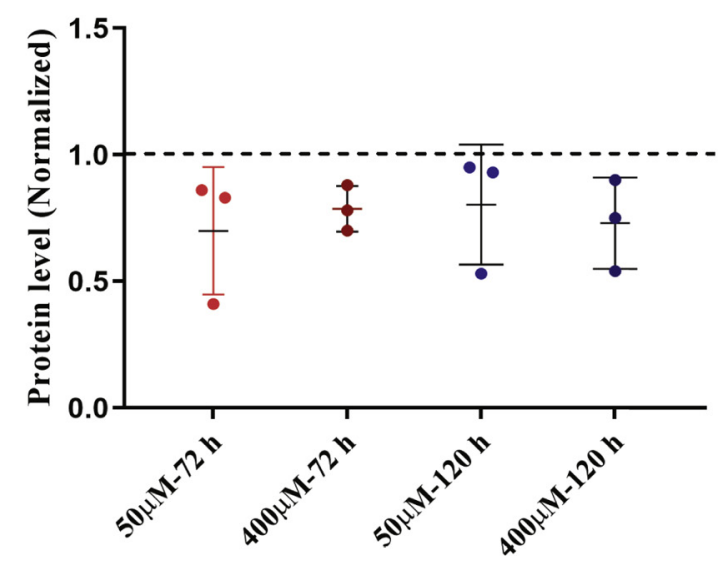

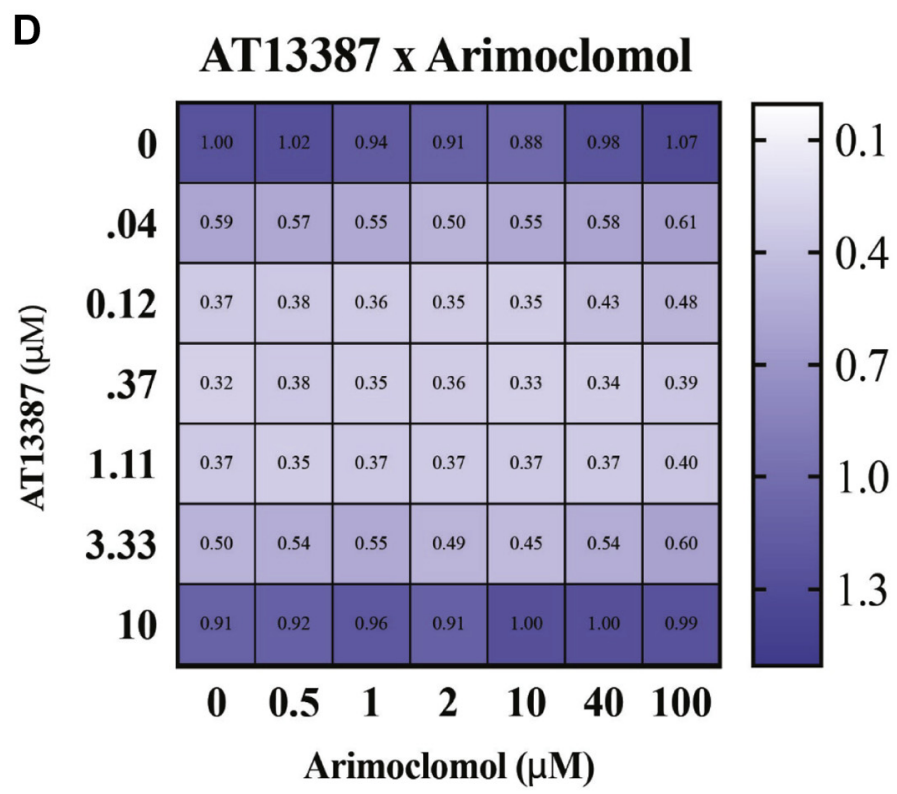

Fig. 7. A: Effect of HSP70 coinducer arimoclomol on NPC1 human fibroblasts: GM18453 fibroblasts were treated with HSP70 activator arimoclomol for $72 \mathrm{~h}$ or $120 \mathrm{~h}$ at doses ranging from 50 to $500 \mu \mathrm{M}$, fixed, and stained with filipin and Draq5. Images were acquired on ImageXpress ${ }^{\text {Micro }}$ using a 10× objective. Each data point is an average of 48 images. Each image contain $~ 500-700$ cells. Each data point in the plot is from three independent experiments \pm SE. B: Western blot of arimoclomol-treated NPC1 human fibroblast: GM18453 fibroblasts were treated with HSP70 activator arimoclomol for $72 \mathrm{~h}$ or $120 \mathrm{~h}$ at $50-400 \mu \mathrm{M}$. Cells were lysed, and Western blot was run using protocol described in the Materials and methods section. Membrane was probed with p-Rab-anti-HSP70 and p-Rab-anti-GAPDH antibodies. Bands were visualized using ECL on a Licor Fc system and quantified. C: Data in plot are from three independent experiments. There was no significant difference in HSP70 expression compared with DMSO-treated cells. Error 
heat stress (85). It will be valuable in the future to explore treatments that enhance HSP70 activity (and other chaperones) for the treatment of NPCl disease.

We tested arimoclomol treatment on disease-relevant $N P C 1^{I 1061 T}$ cells, which was previously reported to enhance HSP70 as well as HSF1 activation in $\mathrm{NPC}^{-/-}$ cells (34). However, we did not observe any reduction in cholesterol storage in $N P C 1^{I 1061 T}$ cells at concentrations up to $0.5 \mathrm{mM}$ for 3 or 5 days. Nor did we see any increase in HSP70 expression in $N P C 1^{11061 T}$ cells after arimoclomol treatment (Fig. 5B, C). A related compound, bimoclomol, has been reported to enhance stress responses but it requires a mild independent activation of stress for this effect (86). It is possible that this type of stress was not present in our cells. Based on the reports of increased HSF1 activation upon arimoclomol treatment and a study reporting combination treatment of arimoclomol with celastrol-an HSF1activating compound $(34,79)$, we treated $N P C 1^{I 1061 T}$ cells with a combination of arimoclomol and an HSF1activating compound (HSFla) (80, 81). This did not yield any additional correction of the NPCl phenotype. In contrast when we combined arimoclomol with AT13387 compound, which has shown to correct the NPC1 phenotype (Fig. 1), we did observe the expected correction from AT13387, but there was no synergistic enhancement by arimoclomol combination treatment (Fig. 7D). Taken together, our data suggest that the therapeutic effect of arimoclomol treatment on $\mathrm{NPCl}^{-/-}$cells might be due to off-target effects since arimoclomol has been reported to inhibit several key regulatory enzymes at micromolar concentrations (87).

This result suggests that further exploration of the mechanism of action of arimoclomol is warranted especially since the pharmaceutical form of arimoclomol is currently undergoing clinical trials (https:// ClinicalTrials.gov/show/NCT02612129) (77). There are numerous mutations reported in the human NPC1 gene that are associated with NPC1 disease $(2,3,5,7)$. The most common mutant protein, $N P C 1^{I 1061 T}$, exits the ER inefficiently and is mostly degraded (18). We have previously shown that several other NPCl missense mutations could function if they could pass through the ER quality control processing. In this study, we only tested $N P C 1^{I 1061 T}$, but we found that the results were very similar to HDACi treatment in that we observed increased protein stability and proper localization of the mutant protein. In conclusion, we report here the therapeutic potential of pan HSP90 inhibitors or HSP90A-selective inhibitors for the treatment of NPC1 disease. Efforts are under way to test these compounds in a mouse model. We note that although TAS-116 is not as potent as other HSP90 inhibitors tested, it is selective for HSP90 $\alpha$ and HSP90 $\beta$ (70) in the cytosol/nucleus and does not target GRP94 in ER and tumor necrosis factor receptor-associated protein 1 in mitochondria. In addition, unlike the other HSP90 inhibitors, TAS-116 is an oral drug that is currently in phase 3 clinical trial of gastrointestinal stromal tumors $(88,89)$. The promising effect of HSP90 inhibition and HSP70 overexpression provides a basis for further investigations of protein chaperones in the treatment of NPCl disease.

\section{Data availability}

Most data are included in the article. Other data may be obtained upon request to Frederick R. Maxfield, Weill Cornell Medical College, frmaxfie@med.cornell. edu. ifr

\section{Supplemental data}

This article contains supplemental data (43).

\section{Author contributions}

N. H. P. conceptualization; L. N. methodology; N. H. P., S. Z. S., K. S., A. C., A. a.-M., K. G., and B. S. J. B. investigation; N. H. P., S. Z. S., K. S., B. S. J. B., L. N., P. H., O. W., D. S. O., and F. R. M. writing-review and editing; B. S. J. B., P. H., O. W., D. S. O., and F. R. M. supervision; N. H. P., P. H., O. W., D. S. O., and F. R. M. funding acquisition.

Author ORCIDs

Nina H. Pipalia (10) https:/ / orcid.org/0000-0002-7619-7351 Frederick R. Maxfield (10) https://orcid.org/0000-0003-43968866

\section{Funding and additional information}

This work was supported in part by grants from the National Institutes of Health, R01-NS092653 (D. S. O., F. R. M., P. H., and O. W.) and R01-CA213566 (B. S. J. B.), by grants from the Ara Parseghian Medical Research Foundation (D. S. O., F. R. M., P. H., and O. W.), by a grant from MDBR-UPenn Orphan Disease Center (N. H. P.), by a grant from the Harrington Discovery Institute (D. S. O.), and by grants from Dana's Angels Research Trust (D. S. O. and F. R. M.). The content is solely the responsibility of the authors and does not necessarily represent the official views of the National Institutes of Health.

\section{Conflict of interest}

The authors declare that they have no conflicts of interest with the contents of this article.

bars represent SE. C: Plot showing quantification of immunoblot bands from DMSO or 50 and $400 \mu \mathrm{M}$ arimoclomol treated NPC1 fibroblasts for 72 and $120 \mathrm{~h}$. Data were normalized to tubulin and DMSO-treated fibroblasts. Dotted indicates DMSO control. No statistically significant difference was observed. D: Cotreatment of AT13387 and arimoclomol on GM18453 NPC1 fibroblasts. GM18453 fibroblasts were plated in 384-well plates and coincubated with arimoclomol and HSP90 inhibitor AT13387 in a dosedependent manner for $72 \mathrm{~h}$. Heat map value represents the average PFI of three independent experiments with four replicate per wells per plate, each image had 100-300 cells, normalized to DMSO-treated cells. LSO values less than one represent a decrease in cholesterol storage, and values greater than one identify an increase in cholesterol storage. 


\section{Abbreviations}

DMSO, dimethyl sulfoxide; EndoH, endoglycosidase H; EndoH $^{\mathrm{R}}$, EndoH-resistant; EndoH ${ }^{\mathrm{S}}$, EndoH-sensitive; ER, endoplasmic reticulum; GRP94, glucose regulated protein 94; HDACi, histone deacetylase inhibitor; HPCD, 2hydroxypropyl beta-cyclodextrin; HSF1, heat shock transcription factor 1; LE/Ly, late endosomes and lysosomes; NPC1, Niemann-Pick type C1; PFA, paraformaldehyde; PFI, perinuclear filipin intensity.

Manuscript received April 21, 2021, and in revised from July 30, 2021. Published, JLR Papers in Press, September 3, 2021, https://doi.org/10.1016/j.jlr.2021.100114

\section{REFERENCES}

1. Patterson, M. C., Clayton, P., Gissen, P., Anheim, M., Bauer, P., Bonnot, O., Dardis, A., Dionisi-Vici, C., Klunemann, H. H., Latour, P., Lourenco, C. M., Ory, D. S., Parker, A., Pocovi, M., Strupp, M., et al. (2017) Recommendations for the detection and diagnosis of Niemann-Pick disease type C: An update. Neurol. Clin. Pract. 7, 499-511

2. Fernandez-Valero, E. M., Ballart, A., Iturriaga, C., Lluch, M., Macias, J., Vanier, M. T., Pineda, M., and Coll, M. J. (2005) Identification of 25 new mutations in 40 unrelated Spanish Niemann-Pick type C patients: genotype-phenotype correlations. Clin. Genet. 68, 245-254

3. Park, W. D., O'Brien, J. F., Lundquist, P. A., Kraft, D. L., Vockley, C. W., Karnes, P. S., Patterson, M. C., and Snow, K. (2003) Identification of 58 novel mutations in Niemann-Pick disease type C: correlation with biochemical phenotype and importance of PTC1-like domains in NPC1. Hum. Mutat. 22, 313-325

4. Polese-Bonatto, M., Bock, H., Farias, A. C. S., Mergener, R., Matte, M. C., Gil, M. S., Nepomuceno, F., Souza, F. T. S., Gus, R., Giugliani, R., and Saraiva-Pereira, M. L. (2019) Niemann-Pick disease type C: Mutation spectrum and novel sequence variations in the human NPCl gene. Mol. Neurobiol. 56, 6426-6435

5. Vanier, M. T. (2010) [Niemann-Pick C disease: history, current research topics, biological and molecular diagnosis]. Arch. Pediatr. 17 Suppl 2, S41-44

6. Vanier, M. T. (2015) Complex lipid trafficking in Niemann-Pick disease type C. J. Inherit. Metab. Dis. 38, 187-199

7. Vanier, M. T. (2010) Niemann-Pick disease type C. Orphanet J. Rare Dis. 5, 16

8. Imrie, J., Heptinstall, L., Knight, S., and Strong, K. (2015) Observational cohort study of the natural history of Niemann-Pick disease type $\mathrm{C}$ in the UK: a 5-year update from the UK clinical database. BMC Neurol. 15, 257

9. Jahnova, H., Dvorakova, L., Vlaskova, H., Hulkova, H., Poupetova, H., Hrebicek, M., and Jesina, P. (2014) Observational, retrospective study of a large cohort of patients with Niemann-Pick disease type $\mathrm{C}$ in the Czech Republic: a surprisingly stable diagnostic rate spanning almost 40 years. Orphanet J. Rare Dis. 9, 140

10. Patterson, M. C., Mengel, E., Wijburg, F. A., Muller, A., Schwierin, B., Drevon, H., Vanier, M. T., and Pineda, M. (2013) Disease and patient characteristics in NP-C patients: findings from an international disease registry. Orphanet J. Rare Dis. 8, 12

11. Gelsthorpe, M. E., Baumann, N., Millard, E., Gale, S. E., Langmade, S. J., Schaffer, J. E., and Ory, D. S. (2008) Niemann-Pick type C1 I1061T mutant encodes a functional protein that is selected for endoplasmic reticulum-associated degradation due to protein misfolding. J. Biol. Chem. 283, 8229-8236

12. Nakasone, N., Nakamura, Y. S., Higaki, K., Oumi, N., Ohno, K., and Ninomiya, H. (2014) Endoplasmic reticulum-associated degradation of Niemann-Pick Cl: evidence for the role of heat shock proteins and identification of lysine residues that accept ubiquitin. J. Biol. Chem. 289, 19714-19725

13. Schultz, M. L., Krus, K. L., and Lieberman, A. P. (2016) Lysosome and endoplasmic reticulum quality control pathways in Niemann-Pick type C disease. Brain Res. 1649, 181-188

14. Wang, C., Scott, S. M., Sun, S., Zhao, P., Hutt, D. M., Shao, H., Gestwicki, J. E., and Balch, W. E. (2020) Individualized management of genetic diversity in Niemann-Pick C1 through modulation of the Hsp70 chaperone system. Hum. Mol. Genet. 29, $1-19$

15. Greer, W. L., Dobson, M. J., Girouard, G. S., Byers, D. M., Riddell, D. C., and Neumann, P. E. (1999) Mutations in NPCl highlight a conserved NPC1-specific cysteine-rich domain. Am. J. Hum. Genet. 65, 1252-1260

16. Loftus, S. K., Morris, J. A., Carstea, E. D., Gu, J. Z., Cummings, C., Brown, A., Ellison, J., Ohno, K., Rosenfeld, M. A., Tagle, D. A., Pentchev, P. G., and Pavan, W. J. (1997) Murine model of Niemann-Pick C disease: mutation in a cholesterol homeostasis gene. Science. 277, 232-235

17. Carstea, E. D., Morris, J. A., Coleman, K. G., Loftus, S. K., Zhang, D., Cummings, C., Gu, J., Rosenfeld, M. A., Pavan, W. J., Krizman, D. B., Nagle, J., Polymeropoulos, M. H., Sturley, S. L., Ioannou, Y. A., Higgins, M. E., et al. (1997) Niemann-Pick Cl disease gene: homology to mediators of cholesterol homeostasis. Science. 277, 228-231

18. Pipalia, N. H., Subramanian, K., Mao, S., Ralph, H., Hutt, D. M., Scott, S. M., Balch, W. E., and Maxfield, F. R. (2017) Histone deacetylase inhibitors correct the cholesterol storage defect in most Niemann-Pick C1 mutant cells. J. Lipid Res. 58, 695-708

19. Ory, D. S., Ottinger, E. A., Farhat, N. Y., King, K. A., Jiang, X., Weissfeld, L., Berry-Kravis, E., Davidson, C. D., Bianconi, S., Keener, L. A., Rao, R., Soldatos, A., Sidhu, R., Walters, K. A., Xu, X., et al. (2017) Intrathecal 2-hydroxypropyl-beta-cyclodextrin decreases neurological disease progression in Niemann-Pick disease, type Cl: a non-randomised, open-label, phase 1-2 trial. Lancet. 390, 1758-1768

20. Farmer, C. A., Thurm, A., Farhat, N., Bianconi, S., Keener, L. A., and Porter, F. D. (2019) Long-term neuropsychological outcomes from an open-label Phase I/IIa trial of 2-hydroxypropyl- $\beta$-cyclodextrins (VTS-270) in Niemann-Pick disease, type Cl. CNS Drugs. 33, 677-683

21. Pipalia, N. H., Cosner, C. C., Huang, A., Chatterjee, A., Bourbon, P., Farley, N., Helquist, P., Wiest, O., and Maxfield, F. R. (2011) Histone deacetylase inhibitor treatment dramatically reduces cholesterol accumulation in Niemann-Pick type Cl mutant human fibroblasts. Proc. Natl. Acad. Sci. U. S. A. 108, 5620-5625

22. Praggastis, M., Tortelli, B., Zhang, J., Fujiwara, H., Sidhu, R., Chacko, A., Chen, Z., Chung, C., Lieberman, A. P., Sikora, J., Davidson, C., Walkley, S. U., Pipalia, N. H., Maxfield, F. R., Schaffer, J. E., et al. (2015) A murine Niemann-Pick C1 I1061T knock-in model recapitulates the pathological features of the most prevalent human disease allele. J. Neurosci. 35, 8091-8106

23. Davidson, J., Molitor, E., Moores, S., Gale, S. E., Subramanian, K., Jiang, X., Sidhu, R., Kell, P., Zhang, J., Fujiwara, H., Davidson, C., Helquist, P., Melancon, B. J., Grigalunas, M., Liu, G., et al. (2019) 2Hydroxypropyl-beta-cyclodextrin is the active component in a triple combination formulation for treatment of Niemann-Pick $\mathrm{Cl}$ disease. Biochim. Biophys. Acta Mol. Cell Biol. Lipids. 1864, $1545-1561$

24. Yu, T., Chung, C., Shen, D., Xu, H., and Lieberman, A. P. (2012) Ryanodine receptor antagonists adapt NPCl proteostasis to ameliorate lipid storage in Niemann-Pick type C disease fibroblasts. Hum. Mol. Genet. 21, 3205-3214

25. Fukuda, H., Karaki, F., Dodo, K., Noguchi-Yachide, T., Ishikawa, M., Hashimoto, Y., and Ohgane, K. (2017) Phenanthridin-6-one derivatives as the first class of non-steroidal pharmacological chaperones for Niemann-Pick disease type Cl protein. Bioorg. Med. Chem. Lett. 27, 2781-2787

26. Ohgane, K., Karaki, F., Noguchi-Yachide, T., Dodo, K., and Hashimoto, Y. (2014) Structure-activity relationships of oxysterol-derived pharmacological chaperones for NiemannPick type C1 protein. Bioorg. Med. Chem. Lett. 24, 3480-3485

27. Wanczyk, M., Roszczenko, K., Marcinkiewicz, K., Bojarczuk, K., Kowara, M., and Winiarska, M. (2011) HDACi-going through the mechanisms. Front. Biosci. 16, 340-359

28. Zhang, C., Yang, C., Feldman, M. J., Wang, H., Pang, Y., Maggio, D. M., Zhu, D., Nesvick, C. L., Dmitriev, P., Bullova, P., Chittiboina, P., Brady, R. O., Pacak, K., and Zhuang, Z. (2017) Vorinostat suppresses hypoxia signaling by modulating nuclear translocation of hypoxia inducible factor 1 alpha. Oncotarget. 8, $56110-56125$

29. Subramanian, K., Rauniyar, N., Lavallee-Adam, M., Yates 3rd, J. R., and Balch, W. E. (2017) Quantitative analysis of the proteome response to the histone deacetylase inhibitor 
(HDACi) vorinostat in Niemann-Pick type C1 disease. Mol. Cell Proteomics. 16, 1938-1957

30. Butler, L. M., Ferraldeschi, R., Armstrong, H. K., Centenera, M. M., and Workman, P. (2015) Maximizing the therapeutic potential of HSP90 inhibitors. Mol. Cancer Res. 13, 1445-1451

31. Jayaraj, G. G., Hipp, M. S., and Hartl, F. U. (2020) Functional modules of the proteostasis network. Cold Spring Harb Perspect. Biol. 12, a033951

32. Cha, J. R., St Louis, K. J., Tradewell, M. L., Gentil, B. J., Minotti, S., Jaffer, Z. M., Chen, R., Rubenstein, A. E., and Durham, H. D. (2014) A novel small molecule HSP90 inhibitor, NXD30001, differentially induces heat shock proteins in nervous tissue in culture and in vivo. Cell Stress Chaperones. 19, 421-435

33. Sittler, A., Lurz, R., Lueder, G., Priller, J., Lehrach, H., HayerHartl, M. K., Hartl, F. U., and Wanker, E. E. (2001) Geldanamycin activates a heat shock response and inhibits huntingtin aggregation in a cell culture model of Huntington's disease. Hum. Mol. Genet. 10, 1307-1315

34. Kirkegaard, T., Gray, J., Priestman, D. A., Wallom, K. L., Atkins, J. Olsen, O. D., Klein, A., Drndarski, S., Petersen, N. H., Ingemann, L., Smith, D. A., Morris, L., Bornaes, C., Jorgensen, S. H., Williams, I., et al. (2016) Heat shock protein-based therapy as a potential candidate for treating the sphingolipidoses. Sci. Transl. Med. 8, 355 ral18

35. Kaur, J., Bhardwaj, A., Melancon, B. J., and Blagg, B. S. J. (2019) The succinct synthesis of AT13387, a clinically relevant Hsp90 inhibitor. Synth. Commun. 49, 1436-1443

36. Xu, X. L., Bao, Q. C., Jia, J. M., Liu, F., Guo, X. K., Zhang, M. Y. Wei, J. L., Lu, M. C., Xu, L. L., Zhang, X. J., You, Q. D., and Sun, H. P. (2016) CPUY201112, a novel synthetic small-molecule compound and inhibitor of heat shock protein Hsp90, induces p53mediated apoptosis in MCF-7 cells. Sci. Rep. 6, 19004

37. Tsai, Y. C., Leu, S. Y., Chen, S. Y., Kung, C. W., Lee, Y. M., Liu, Y. P., Yen, M. H., and Cheng, P. Y. (2019) 17-DMAG, an Hsp90 inhibitor, ameliorates ovariectomy-induced obesity in rats. Life Sci. 232, 116672

38. Herbst, M., and Wanker, E. E. (2007) Small molecule inducers of heat-shock response reduce polyQ-mediated huntingtin aggregation. A possible therapeutic strategy. Neurodegener. Dis. 4, 254-260

39. Gibbs, S. J., Barren, B., Beck, K. E., Proft, J., Zhao, X., Noskova, T. Braun, A. P., Artemyev, N. O., and Braun, J. E. (2009) Hsp40 couples with the CSPalpha chaperone complex upon induction of the heat shock response. PLoS One. 4, e4595

40. Basu, S. K., Goldstein, J. L., Anderson, G. W., and Brown, M. S. (1976) Degradation of cationized low density lipoprotein and regulation of cholesterol metabolism in homozygous familial hypercholesterolemia fibroblasts. Proc. Natl. Acad. Sci. U.S.A. 73, 3178-3182

41. Grosheva, I., Haka, A. S., Qin, C., Pierini, L. M., and Maxfield, F. R. (2009) Aggregated LDL in contact with macrophages induces local increases in free cholesterol levels that regulate local actin polymerization. Arterioscler. Thromb. Vasc. Biol. 29, 1615-1621

42. Havel, R. J., Eder, H. A., and Bragdon, J. H. (1955) The distribution and chemical composition of ultracentrifugally separated lipoproteins in human serum. J. Clin. Invest. 34, 1345-1353

43. Pipalia, N. H., Huang, A., Ralph, H., Rujoi, M., and Maxfield, F. R. (2006) Automated microscopy screening for compounds that partially revert cholesterol accumulation in Niemann-Pick C cells. J. Lipid Res. 47, 284-301

44. Dunn, K. W., Kamocka, M. M., and McDonald, J. H. (2011) A practical guide to evaluating colocalization in biological microscopy. Am. J. Physiol. Cell Physiol. 300, C723-742

45. Dunn, K. W., and Maxfield, F. R. (1992) Delivery of ligands from sorting endosomes to late endosomes occurs by maturation of sorting endosomes. J. Cell Biol. 117, 301-310

46. Pugach, E. K., Feltes, M., Kaufman, R. J., Ory, D. S., and Bang, A G. (2018) High-content screen for modifiers of Niemann-Pick type C disease in patient cells. Hum. Mol. Genet. 27, 2101-2112

47. Chai, R. C., Vieusseux, J. L., Lang, B. J., Nguyen, C. H., Kouspou, M. M., Britt, K. L., and Price, J. T. (2017) Histone deacetylase activity mediates acquired resistance towards structurally diverse HSP90 inhibitors. Mol. Oncol. 11, 567-583

48. Choi, H. K., and Lee, K. (2012) Recent updates on the development of ganetespib as a Hsp90 inhibitor. Arch. Pharm. Res. 35, $1855-1859$
49. Canella, A., Welker, A. M., Yoo, J. Y., Xu, J., Abas, F. S., Kesanakurti, D., Nagarajan, P., Beattie, C. E., Sulman, E. P., Liu, J., Gumin, J., Lang, F. F., Gurcan, M. N., Kaur, B., Sampath, D., et al. (2017) Efficacy of onalespib, a long-acting second-generation HSP90 inhibitor, as a single agent and in combination with temozolomide against malignant gliomas. Clin. Cancer Res. 23, 6215-6226

50. Kang, M. H., Reynolds, C. P., Houghton, P. J., Alexander, D., Morton, C. L., Kolb, E. A., Gorlick, R., Keir, S. T., Carol, H., Lock, R., Maris, J. M., Wozniak, A., and Smith, M. A. (2012) Initial testing (Stage 1) of AT13387, an HSP90 inhibitor, by the pediatric preclinical testing program. Pediatr. Blood Cancer. 59, 185-188

51. Woodhead, A. J., Angove, H., Carr, M. G., Chessari, G., Congreve, M., Coyle, J. E., Cosme, J., Graham, B., Day, P. J., Downham, R. Fazal, L., Feltell, R., Figueroa, E., Frederickson, M., Lewis, J., et al. (2010) Discovery of (2,4-dihydroxy-5-isopropylphenyl)-[5-(4methylpiperazin-1-ylmethyl)-1,3-dihydrois oindol-2-yl]methanone (AT13387), a novel inhibitor of the molecular chaperone Hsp90 by fragment based drug design. J. Med. Chem. 53, 5956-5969

52. Li, O. O., Hao, J. J., Zhang, Z., Krane, L. S., Hammerich, K. H Sanford, T., Trepel, J. B., Neckers, L., and Agarwal, P. K. (2017) Proteomic analysis of proteome and histone post-translational modifications in heat shock protein 90 inhibition-mediated bladder cancer therapeutics. Sci. Rep. 7, 201

53. Uno, T., Kawai, Y., Yamashita, S., Oshiumi, H., Yoshimura, C, Mizutani, T., Suzuki, T., Chong, K. T., Shigeno, K., Ohkubo, M. Kodama, Y. Muraoka, H., Funabashi, K., Takahashi, K., Ohkubo, S., et al. (2019) Discovery of 3-ethyl-4-(3-isopropyl-4-(4-(1-methyl-1 H-pyrazol-4-yl)-1 H-imidazole-1-yl)-1 H-pyrazolo[3,4- b]pyridin-1yl)benzamide (TAS-116) as a potent, selective, and orally available HSP90 inhibitor. J. Med. Chem. 62, 531-551

54. Chai, K., Ning, X., Nguyen, T. T. T., Zhong, B., Morinaga, T., Li, Z Shingyoji, M., Tada, Y., Tatsumi, K., Shimada, H., Hiroshima, K., Yamaguchi, N., and Tagawa, M. (2018) Heat shock protein 90 inhibitors augment endogenous wild-type p53 expression but down-regulate the adenovirally-induced expression by inhibiting a proteasome activity. Oncotarget. 9, 26130-26143

55. Banerjee, M., Hatial, I., Keegan, B. M., and Blagg, B. S. J. (2021) Assay design and development strategies for finding Hsp90 inhibitors and their role in human diseases. Pharmacol. Ther. 221 , 107747

56. Sun, H. P., Jia, J. M., Jiang, F., Xu, X. L., Liu, F., Guo, X. K., Cherfaoui, B., Huang, H. Z., Pan, Y., and You, O. D. (2014) Identification and optimization of novel Hsp90 inhibitors with tetrahydropyrido[4,3-d]pyrimidines core through shape-based screening. Eur. J. Med. Chem. 79, 399-412

57. Wang, L., Jiang, J., Zhang, L., Zhang, Q., Zhou, J., Li, L., Xu, X. and You, Q. (2020) Discovery and optimization of small molecules targeting the protein-protein interaction of heat shock protein 90 (Hsp90) and cell division cycle 37 as orally active inhibitors for the treatment of colorectal cancer. J. Med. Chem. 63, 1281-1297

58. Yao, H., Xu, F., Wang, G., Xie, S., Li, W., Yao, H., Ma, C., Zhu, Z., $\mathrm{Xu}$, J., and Xu, S. (2019) Design, synthesis, and biological evaluation of truncated deguelin derivatives as Hsp90 inhibitors. Eur. J. Med. Chem. 167, 485-498

59. Taldone, T., Patel, P. D., Patel, M., Patel, H. J., Evans, C. E., Rodina, A., Ochiana, S., Shah, S. K., Uddin, M., Gewirth, D., and Chiosis, G. (2013) Experimental and structural testing module to analyze paralogue-specificity and affinity in the Hsp90 inhibitors series. J. Med. Chem. 56, 6803-6818

60. Karten, B., Vance, D. E., Campenot, R. B., and Vance, J. E. (2002) Cholesterol accumulates in cell bodies, but is decreased in distal axons, of Niemann-Pick Cl-deficient neurons. J. Neurochem. 83, $1154-1163$

61. Rosenbaum, A. I., Zhang, G., Warren, J. D., and Maxfield, F. R. (2010) Endocytosis of beta-cyclodextrins is responsible for cholesterol reduction in Niemann-Pick type C mutant cells. Proc. Natl. Acad. Sci. U.S.A. 107, 5477-5482

62. Rauniyar, N., Subramanian, K., Lavallee-Adam, M., MartinezBartolome, S., Balch, W. E., and Yates 3rd., J. R. (2015) Quantitative proteomics of human fibroblasts with I1061T mutation in Niemann-Pick C1 (NPCl) protein provides insights into the disease pathogenesis. Mol. Cell Proteomics. 14, 1734-1749

63. Subramanian, K., Hutt, D. M., Scott, S. M., Gupta, V., Mao, S., and Balch, W. E. (2020) Correction of Niemann-Pick type C1 trafficking and activity with the histone deacetylase inhibitor valproic acid. J. Biol. Chem. 295, 8017-8035 
64. Wang, C., Scott, S. M., Subramanian, K., Loguercio, S., Zhao, P., Hutt, D. M., Farhat, N. Y., Porter, F. D., and Balch, W. E. (2019) Quantitating the epigenetic transformation contributing to cholesterol homeostasis using Gaussian process. Nat. Commun. 10, 5052

65. Ghosh, R. N., Gelman, D. L., and Maxfield, F. R. (1994) Quantification of low density lipoprotein and transferrin endocytic sorting HEp2 cells using confocal microscopy. J. Cell Sci. 107 (Pt 8), 2177-2189

66. Mukherjee, S., Ghosh, R. N., and Maxfield, F. R. (1997) Endocytosis. Physiol. Rev. 77, 759-803

67. Baldo, B., Weiss, A., Parker, C. N., Bibel, M., Paganetti, P., and Kaupmann, K. (2012) A screen for enhancers of clearance identifies huntingtin as a heat shock protein 90 (Hsp90) client protein. J. Biol. Chem. 287, 1406-1414

68. Vega, V. L., Charles, W., and De Maio, A. (2010) A new feature of the stress response: increase in endocytosis mediated by Hsp70. Cell Stress Chaperones. 15, 517-527

69. Mayor-Lopez, L., Tristante, E., Carballo-Santana, M., CarrascoGarcia, E., Grasso, S., Garcia-Morales, P., Saceda, M., Lujan, J., Garcia-Solano, J., Carballo, F., de Torre, C., and Martinez-Lacaci, I. (2014) Comparative study of 17-AAG and NVP-AUY922 in pancreatic and colorectal cancer cells: are there common determinants of sensitivity? Transl. Oncol. 7, 590-604

70. Ohkubo, S., Kodama, Y., Muraoka, H., Hitotsumachi, H., Yoshimura, C., Kitade, M., Hashimoto, A., Ito, K., Gomori, A., Takahashi, K., Shibata, Y., Kanoh, A., and Yonekura, K. (2015) TAS116 , a highly selective inhibitor of heat shock protein 90alpha and beta, demonstrates potent antitumor activity and minimal ocular toxicity in preclinical models. Mol. Cancer Ther. 14, 14-22

71. Richter, K., Reinstein, J., and Buchner, J. (2007) A Grp on the Hsp90 mechanism. Mol. Cell. 28, 177-179

72. Crowley, V. M., Huard, D. J. E., Lieberman, R. L., and Blagg, B. S. J. (2017) Second generation Grp94-selective inhibitors provide opportunities for the inhibition of metastatic cancer. Chemistry. 23, 15775-15782

73. Crowley, V. M., Khandelwal, A., Mishra, S., Stothert, A. R., Huard, D. J., Zhao, J., Muth, A., Duerfeldt, A. S., Kizziah, J. L., Lieberman, R. L., Dickey, C. A., and Blagg, B. S. (2016) Development of glucose regulated protein 94-selective inhibitors based on the BnIm and Radamide scaffold. J. Med. Chem. 59, 3471-3488

74. Khandelwal, A., Crowley, V. M., and Blagg, B. S. J. (2017) Resorcinol-based Grp94-selective inhibitors. ACS Med. Chem. Lett. 8, 1013-1018

75. Khandelwal, A., Kent, C. N., Balch, M., Peng, S., Mishra, S. J., Deng, J., Day, V. W., Liu, W., Subramanian, C., Cohen, M., Holzbeierlein, J. M., Matts, R., and Blagg, B. S. J. (2018) Structureguided design of an Hsp90beta N-terminal isoform-selective inhibitor. Nat. Commun. 9, 425

76. Mishra, S. J., Ghosh, S., Stothert, A. R., Dickey, C. A., and Blagg, B. S. (2017) Transformation of the non-selective aminocyclohexanolbased Hsp90 inhibitor into a Grp94-seletive scaffold. ACS Chem. Biol. 12, 244-253

77. Mengel, E., Patterson, M. C., Da Riol, R. M., Del Toro, M., Deodato, F., Gautschi, M., Grunewald, S., Grønborg, S., Harmatz, P., Héron, B., Maier, E. M., Roubertie, A., Santra, S., Tylki-Szymanska, A., Day, S., et al. (2021) Efficacy and safety of arimoclomol in Niemann-Pick disease type C: results from a doubleblind, randomised, placebo-controlled, multinational phase $2 / 3$ trial of a novel treatment. J. Inherit. Metab. Dis. https://doi.org/10. 1002/jimd.12428. Epub ahead of print. August 21, 2021
78. Anckar, J., and Sistonen, L. (2011) Regulation of HSF1 function in the heat stress response: implications in aging and disease. Annu. Rev. Biochem. 80, 1089-1115

79. Deane, C. A., and Brown, I. R. (2016) Induction of heat shock proteins in differentiated human neuronal cells following co-application of celastrol and arimoclomol. Cell Stress Chaperones. 21, 837-848

80. Neef, D. W., Jaeger, A. M., Gomez-Pastor, R., Willmund, F., Frydman, J., and Thiele, D. J. (2014) A direct regulatory interaction between chaperonin $\mathrm{TRiC}$ and stress-responsive transcription factor HSF1. Cell Rep. 9, 955-966

81. Neef, D. W., Turski, M. L., and Thiele, D. J. (2010) Modulation of heat shock transcription factor 1 as a therapeutic target for small molecule intervention in neurodegenerative disease. PLoS Biol. 8, e1000291

82. Kirkegaard, T., Roth, A. G., Petersen, N. H., Mahalka, A. K., Olsen, O. D., Moilanen, I., Zylicz, A., Knudsen, J., Sandhoff, K., Arenz, C., Kinnunen, P. K., Nylandsted, J., and Jaattela, M. (2010) Hsp70 stabilizes lysosomes and reverts Niemann-Pick diseaseassociated lysosomal pathology. Nature. 463, 549-553

83. Moses, M. A., Kim, Y. S., Rivera-Marquez, G. M., Oshima, N., Watson, M. J., Beebe, K. E., Wells, C., Lee, S., Zuehlke, A. D., Shao, H., Bingman 3rd, W. E., Kumar, V., Malhotra, S. V., Weigel, N. L., Gestwicki, J. E., et al. (2018) Targeting the Hsp40/Hsp70 chaperone axis as a novel strategy to treat castration-resistant prostate cancer. Cancer Res. 78, 4022-4035

84. Shao, H., Li, X., Moses, M. A., Gilbert, L. A., Kalyanaraman, C., Young, Z. T., Chernova, M., Journey, S. N., Weissman, J. S., Hann, B., Jacobson, M. P., Neckers, L., and Gestwicki, J. E. (2018) Exploration of benzothiazole rhodacyanines as allosteric inhibitors of protein-protein interactions with heat shock protein 70 (Hsp70). J. Med. Chem. 61, 6163-6177

85. Kijima, T., Prince, T. L., Tigue, M. L., Yim, K. H., Schwartz, H., Beebe, K., Lee, S., Budzynski, M. A., Williams, H., Trepel, J. B., Sistonen, L., Calderwood, S., and Neckers, L. (2018) HSP90 inhibitors disrupt a transient HSP90-HSF1 interaction and identify a noncanonical model of HSP90-mediated HSF1 regulation. Sci. Rep. 8, 6976

86. Vigh, L., Literati, P. N., Horvath, I., Torok, Z., Balogh, G., Glatz, A., Kovacs, E., Boros, I., Ferdinandy, P., Farkas, B., Jaszlits, L., Jednakovits, A., Koranyi, L., and Maresca, B. (1997) Bimoclomol: a nontoxic, hydroxylamine derivative with stress proteininducing activity and cytoprotective effects. Nat. Med. 3, $1150-1154$

87. Atkinson, B. N., Woodward, H. L., Sipthorp, J., and Fish, P. V. (2017) Regioselective and enantiospecific synthesis of the HSP co-inducer arimoclomol from chiral glycidyl derivatives. Org. Biomol. Chem. 15, 9794-9799

88. Doi, T., Kurokawa, Y., Sawaki, A., Komatsu, Y., Ozaka, M., Takahashi, T., Naito, Y., Ohkubo, S., and Nishida, T. (2019) Efficacy and safety of TAS-116, an oral inhibitor of heat shock protein 90 , in patients with metastatic or unresectable gastrointestinal stromal tumour refractory to imatinib, sunitinib and regorafenib: a phase II, single-arm trial. Eur. J. Cancer. 121, 29-39

89. Shimomura, A., Yamamoto, N., Kondo, S., Fujiwara, Y., Suzuki, S., Yanagitani, N., Horiike, A., Kitazono, S., Ohyanagi, F., Doi, T., Kuboki, Y., Kawazoe, A., Shitara, K., Ohno, I., Banerji, U., et al. (2019) First-in-Human Phase I Study of an oral HSP90 Inhibitor, TAS-116, in patients with advanced solid tumors. Mol. Cancer Ther. $18,531-540$ 